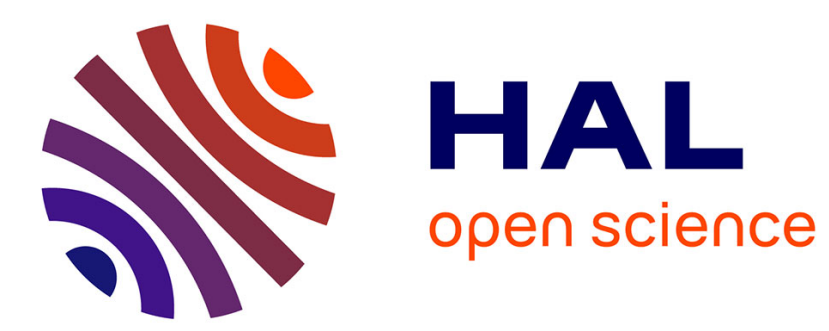

\title{
Stochastic Petropolitics: The Dynamics of Institutions in Resource-Dependent Economies
}

Raouf Boucekkine, Fabien Prieur, Chrysovalantis Vasilakis, Benteng Zou

\section{To cite this version:}

Raouf Boucekkine, Fabien Prieur, Chrysovalantis Vasilakis, Benteng Zou. Stochastic Petropolitics: The Dynamics of Institutions in Resource-Dependent Economies. 2018. halshs-01758376

\section{HAL Id: halshs-01758376 \\ https://shs.hal.science/halshs-01758376}

Preprint submitted on 4 Apr 2018

HAL is a multi-disciplinary open access archive for the deposit and dissemination of scientific research documents, whether they are published or not. The documents may come from teaching and research institutions in France or abroad, or from public or private research centers.
L'archive ouverte pluridisciplinaire HAL, est destinée au dépôt et à la diffusion de documents scientifiques de niveau recherche, publiés ou non, émanant des établissements d'enseignement et de recherche français ou étrangers, des laboratoires publics ou privés. 


\section{amse}

école d'économie d'aix-marseille

aix-marseille school of economics

\section{Working Papers / Documents de travail}

\section{Stochastic Petropolitics: The Dynamics of Institutions in Resource-Dependent Economies}

Raouf Boucekkine

Fabien Prieur

Chrysovalantis Vasilakis

Benteng Zou 


\title{
Stochastic petropolitics: The dynamics of institutions in resource-dependent economies
}

\author{
Raouf Boucekkine* $\quad$ Fabien Prieur ${ }^{\dagger} \quad$ Chrysovalantis Vasilakis $^{\ddagger}$ \\ Benteng $\mathrm{Zou}^{\S}$
}

April 4, 2018

\begin{abstract}
We provide an analysis of institutional dynamics under uncertainty by means of a stochastic differential game of lobbying with two players (conservatives vs liberals) and three main ingredients. The first one is uncertainty inherent in the institutional process itself. The second considers resource windfalls volatility impact on economic and institutional outcomes. Last but not least, the resource windfall level matters in the relative bargaining power of the players. We compute a unique closed-loop equilibrium with linear feedbacks. We show that the legislative state converges to an invariant distribution. Even more importantly, we demonstrate that the most likely asymptotic legislative state is favorable to the liberals. However, the more volatile resource windfalls, the less liberal is the most likely asymptotic state. Finally, we assess the latter prediction on a database covering 91 countries over the period 1973-2005. We focus on financial liberalization policies. We find that as the resources revenues volatility increases, the financial liberalization index goes down. We also find that this property remains robust across different specifications and sample distinctions.
\end{abstract}

Keywords: Institutional dynamics, petropolitics, lobbying games, revenue-dependent lobbying power, stochastic dynamic games, stochastic stability.

JEL classification: D72, C73, Q32

*Aix-Marseille University (Aix-Marseille School of Economics and Institute for Advanced Study), CNRS, EHESS and Institut Universitaire de France. 2 rue de la charité, 13002 Marseille, France. E-mail: Raouf.Boucekkine@univ-amu.fr

${ }^{\dagger}$ EconomiX, University Paris Nanterre. E-mail: fabien.prieur@parisnanterre.fr

${ }^{\ddagger}$ University of Bangor and IRES, Universite Catholique de Louvain, E-mail:c.vasilakis@bangor.ac.uk

$\$$ CREA, University of Luxembourg. 162a, avenue de la Faiencerie, L-1511, Luxembourg. E-mail: benteng.zou@uni.lu 


\section{Introduction}

The link between resource-dependence and quality of institutions is generally viewed through the prism of the resource curse problem: resource-dependent economies are then typically shown to misuse the revenues accruing from exporting the resources (see for example Gylfason, 2001). In particular, there is a lively debate on whether oil and natural resources have an impact on democratization: for example, Ross (2001) and Tsui (2011) argue that oil and natural resources tend to impede democracy. The same view is expressed quite provocatively by Friedman (2006): "Is it an accident that the Arab world's first and only real democracy (Bahrein) happens to not have a drop of oil?". Friedman ends up proposing what he calls the first law of petropolitics: "The price of oil and the pace of freedom always move in opposite directions in oil-rich petrolist states".

Perhaps because there is no compelling empirical evidence of such a law (see for example Alexeev and Conrad, 2009, and Haber and Menaldo, 2011), a new stream of the related theoretical literature has emerged in the recent years pointing at the heterogenous political effects of resource abundance. An excellent representative of this literature is Caselli and Tesei (2016). In an essentially empirical paper, the authors show that while in moderately entrenched autocracies revenue windfalls significantly reinforce the autocratic nature of the political system, they have no effect either in strongly entrenched autocracies or in democracies. A more theoretical contribution is due to Boucekkine et al. (2016) who study the impact of resource abundance on political survival of autocracies. They find that resource abundance plays a role in political transitions only when the elite in office are vulnerable enough, vulnerability being reflected in the low repression capacity of the elite and exacerbated by large income inequality.

While the latter literature exploring the link between the level of resources and the quality of institutions is currently very active, we are not aware of any theory exploring the impact of resource revenues volatility on the internal functioning of the national institutions. The main purpose of the present paper is to close this gap. More specifically, we take petropolitics seriously and develop a stochastic game-theoretic framework to address the validity of Friedman-like laws in such a framework. The basic research question could be formulated as follows: is the volatility of commodity revenues good or bad for the quality of institutions? Does a rising volatility exacerbate the autocratic 
nature of the political systems or does it lead to more liberal regimes?

Our working example is Algeria. A striking feature of Algerian economic policy is that the legislations organizing the openness of the country to foreign goods, capital flows and multinationals have been closely driven by the price of the oil barrel, as detailed in Boucekkine and Bouklia (2011). For example, the Algerian economy has been fiercely closed in the 70s in the times of high barrel price levels, and turned to be significantly liberalized from the mid-80s after the 1986 oil counter-shock and a subsequent acute external debt crisis until 2008 with the resurgence of strongly nationalist policy...coinciding with high price levels again for the oil barrel. The current oil counter-shock is now reversing the political line: the Algerian government has just announced that the 2016 budget will be much more FDI-friendly so as to limit the contractionary effects induced by the necessary adjustment of the balance of payments to the external shock.

As documented by Boucekkine and Bouklia, these sharp variations in economic policy relative to the scope of liberalization are the outcomes of a continuous struggle within the nomenklatura between the representatives of the nationalist (socialist) line and a minority reformist (liberal) wing which has emerged more clearly after the 1986 oil counter-shock. In periods of high oil prices, the nationalist wing is in better position to block the reforms (including political liberalization indeed) simply because the resulting massive inflows of capital (exports revenues) makes less urgent any further opening to foreign investment and the like. ${ }^{1}$ A natural research question is therefore to inquire what could be the equilibrium outcome of such a struggle for a given (stochastic) law of motion for the commodity price (or the commodity revenues), and its long-term implications (existence of stochastic steady states and characterization of their comparative statics).

Of course, we do not claim that the commodity price is the unique determinant of politico-economic equilibria in this type of countries. We also consider a second source of uncertainty, reflecting all the potential internal and/or external shocks affecting directly the political or constitutional state of the country. For example, in

\footnotetext{
${ }^{1}$ In the case of Algeria, things could get even worse in periods of high oil prices, and some proliberalization legislations implemented in the past have been simply cancelled in the good times of the international oil markets (start and stop). This is exactly what happened at the end of the last decade when the Algerian government came to cancel the opening of domestic banks' capital decided in 2003, see Boucekkine and Bouklia (2011).
} 
the Algerian case outlined above, uncertainty also originates in the course of internal politics-electoral competition, successive revisions of the constitution etc., or in external political shocks like the 2011 Arab spring shock. ${ }^{2}$ Another crucial aspect, clearly motivated by the Algerian example, is that revenue windfalls do not only bring instability and volatility into the economies, they do also shape the relative lobbying power of the players. It's at the times where these revenues were perceived by the elite to be persistently high that the opening of domestic bank' capital was canceled. This ingredient is essentially consistent with the Friedman's law as high oil prices would give more power to the nomenklatura's wing blocking liberalization. We shall incorporate it into our model.

Quite naturally, since the problem under scrutiny is all about the struggle between two rival groups (within the elite), we will model the Algerian story told above as a lobbying game, which is itself closely related to the rent-seeking literature (see Tullock, 1967, Kruger, 1974, Tullock again in 1980, or Becker, 1982). Dynamic deterministic versions of the game have been proposed by Leininger and Yang (1994) and Wirl (1994). We shall take the differential game avenue opened by Wirl (1994). It essentially departs from the original game-theoretic lobbying game developed by Tullock (1980) in that the players do not compete for a given prize but invest in rent-seeking to change the state of the institutional arrangements in their favor. This game-theoretic frame fits better the kind of problems we seek to handle. Since our research question is all about uncertainty, we will consider stochastic dynamic versions of this lobbying game, a quite infrequent modeling.

Precisely, from the theoretical point of view, we depart from the original deterministic dynamic lobbying game in two essential ways. First of all, we introduce uncertainty: to mimic the Algerian case, uncertainty affects both the dynamics of the resource revenues and the legislative state. In other words, we have a two-state stochastic game. Depending on the parameterization of the resource revenues process, resources can be renewable or non-renewable, which enriches the discussion. We assume that resource revenues dynamics are autonomous in that they are independent of internal institutional dynamics. In other words, resource revenues are assumed to be independent of the law of motion of the legislative state. This is essentially a small open economy assumption. Recently, van der Ploeg et al. (2017) have argued that most of the recent

\footnotetext{
${ }^{2}$ See again Boucekkine et al. (2016).
} 
hydrocarbons (mostly offshore) discoveries are due to an increasing market orientation in the world, including developing economies (Ghana and Peru being quoted to make the case). We do agree that market orientation is one of the reasons behind the increase in discoveries recently, with the subsequent rise in revenues. This said, the formidable pace of technological progress may also be advocated, especially in what respects offshore explorations. Here we do not take sides in this debate and consider the simple case of windfall revenues, our model is already intricate enough analytically speaking. Second, while the players have equal lobbying power in the original setting, we explicitly model the impact of the stochastic resource revenue on the positions of the two players in the lobbying game: The revenue follows a given brownian motion, larger revenue making the anti-liberal player in better position to block the legislation in favor of economic openness or liberalization.

When shutting down the two sources of uncertainty, the (deterministic) equilibrium displays convergence to a conservative position in the political spectrum whatever the nature of resources (renewable or not), the asymptotic political position being infinitely conservative in almost all the configurations considered. With identical lobbying powers, one would get the Wirl's result: the economy converges to the center of the political spectrum. Here, by awarding the conservatives a better bargaining position when the resource revenues go up, consistently with the Algerian case, we mostly get conservative political states asymptotically. In such a case, Friedman's first law of petropolitics holds (by construction). However when the uncertainty sources are switched on, we show that revenue volatility tends to stabilize institutional dynamics compared to the deterministic counterpart, which weakens the case for Friedman's first law of petropolitics. Precisely, we show that the legislative state converges to an invariant distribution. Even more importantly, we demonstrate that the most likely asymptotic legislative state is no longer the center of the political spectrum, it is indeed more favorable to the liberal player. In this sense, uncertainty is favorable to liberals. However, the more volatile resource windfalls, the less liberal is the most likely asymptotic state.

A similar result is obtained by Boucekkine et al. (2018a) in the benchmark case without resource revenues: in the latter frame, uncertainty relies on a single source, the legislative state, and players are symmetric in that they have the same bargaining power. ${ }^{3}$ This seems to give some robustness to the property that within this class of

\footnotetext{
${ }^{3}$ Another difference lies in the fact that the payoff functions are quadratic in the legislative state
} 
stochastic games an increase in volatility makes the most likely asymptotic state less liberal. More importantly, we provide with an empirical assessment of the latter prediction. Consistently with the Algerian example described above, we study the impact of volatility of natural resources revenues on financial liberalization. Clearly, other liberalization policies could have been investigated, we restrict our analysis to the former for convenience as constructing an index of all liberalization policies is beyond the scope of this paper. In the study of the impact of resource revenues volatility on financial liberalization, we use a rich set of controls and shocks, including political ones like ideology, and adopt a methodology similar to Abiad and Mody (2005). The financial liberalization index considered is collected from a new database due to Abiad et al. (2008); it covers 91 countries over the period 1973-2005. Our results point to a negative link between the volatility of rents and liberalization. Indeed, we obtain that as the resources revenues volatility increases, the probability to get liberal drops (or in others words, as the volatility goes up, the financial liberalization index goes down). This is consistent with the main prediction of our theoretical framework. We also find that this property remains robust across different specifications and sample distinctions.

The paper is organized as follows. Section 2 briefly presents the general stochastic game. Section 3 studies the equilibrium features of the lobbying game where resource revenue and the dynamics of institutions are driven by two different but related stochastic processes. Most of the discussion is dedicated to the interplay between, uncertainty, stochastic stability and the level of liberalization. In Section 4, we conduct an empirical investigation on the impact of uncertainties on financial liberalization in order to test the main prediction obtained in Section 3. Section 5 concludes.

\section{Model}

We consider a game opposing two rival groups, $i=1,2$, who engage in lobbying efforts, $x_{i} \geq 0$, to push the legislation, $z \in(-\infty, \infty)$, in their preferred direction. The variable $z$ can alternatively be interpreted as the state of economic and/or political liberalization. In both cases, $z$ is an indicator of the quality of institutions, and by convention, the larger $z$, the better the institutions. Players have opposite views on variable in Boucekkine et al. (2018a) while they are linear in this variable in this paper for analytical reasons. See Section 2. 
how the legislation should evolve: Player 1 consists of the reformist group, i.e., wants $z$ to be as high as possible, whereas player 2 exerts efforts to lower $z$. As in Wirl (1994), $z=0$ is the neutral level of legislation, or liberalization. We extend his framework in two essential ways.

First, we take into account the uncertainty surrounding the evolution of $z$. The legislative process is uncertain in the (obvious) sense that the legislation $z$ does not only depend on the investments made by the lobbyists: it also depends on other political, economic, and social circumstances that we account for by making stochastic the law of motion of state $z$. In addition, interpreting $z$ as the level of liberalization, it is fair to say that there are many factors - internal or external shocks - that also affect the evolution of $z$. It is enough to mention the consequences of the Arab Spring events in countries such as Algeria and Morocco where the uprising of the citizens didn't lead to the overthrow of the ruling elite but changed the political system (legislation and policies) quite substantially.

Second, we incorporate the "Algerian story", which basically means that the economy relies on windfall revenues from natural resources, $R$. In the resource-dependent economy, these revenues play a crucial role since they determine the positions of the players in the lobbying game. To fit with the Algerian case, we further assume that the larger $R$, the more efficient is the investment of player 2 in moving the legislation $z$. Note that accounting for the impact of resource windfalls on the relative lobbying power is very much in line with the resource curse hypothesis according to which natural resources wealth tends to make political institutions less democratic, or impairs economic performance (see Ross, 2001, and Tsui, 2010). Of course, considering the impact of resource revenues also rises the question of their evolution in time and requires the volatility of these rents be taken into account (just think about the volatility in the price of oil). This adds a second source of uncertainty to our problem.

In our setting, the two types of uncertainties and the link between $z$ and $R$ are incorporated by means of two stochastic state equations:

$$
\begin{aligned}
d z & =\left[x_{1}-g_{z}(R) x_{2}\right] d t+\sigma_{z} z d W \\
d R & =g_{R}(R) d t+\sigma_{R} R d W
\end{aligned}
$$


where $W=\left(W_{t}\right)_{t \geq 0}$ is a standard Wiener process, ${ }^{4}$ and $\sigma_{i}, i=z, R$, measure volatilities of $z$ and $R$, respectively. Function $g_{z}(R)$ is increasing in $R$, which reflects the fact that player 2 is more efficient in times of high windfalls. In general, function $g_{R}(R)$ may take any form, depending on whether the resources are renewable or not. The important point is that what matters to lobbyists is the resource revenues (they barely control extraction directly anyway), which typically have a deterministic time trend (which can be positive or negative) but are essentially stochastic because of the volatility of international (energy) prices and unpredictable technological innovations or resource discoveries.

In order to keep the model tractable, the game should display a linear-quadratic structure. This leads us to use the following functional forms:

$$
\begin{aligned}
& g_{z}(R)=1+\varepsilon R, \\
& g_{R}(R)=\eta+\xi R,
\end{aligned}
$$

with $\varepsilon \geq 0$, and $\eta, \xi \in \mathbb{R}$. Despite their apparent simplicity, these forms are meaningful enough to conduct the analysis. Indeed, it is quite easy to retrieve the expression of $g_{R}(R)$ in (3) and the dynamics of $R$ given by (2) from two separate state equations in the resource stock, and the resource price. Define $R=p E$ as the resource rent, with $p$ the price (in the absence of market power), and $E$ the extraction (or harvesting) rate. For simplicity let us assume that the extraction rate takes the following form: $E=e S$ with $S$ the stock of resource and $e$ a constant effort representing the share of the stock extracted at each date. This is enough to capture the decreasing time path of extraction over time. Then, define the dynamics of both variables as follows:

$$
\begin{aligned}
& d p=\alpha p d t+\sigma_{p} p d W \\
& d S=(a-e S) d t
\end{aligned}
$$

This boils down to considering uncertainty in the evolution of the price only, which furthermore follows a constant deterministic and positive trend $\alpha$ (this is the simplest version of the Hotelling rule). Combining these two differential equations, we obtain

\footnotetext{
${ }^{4}$ The same Wiener process is used in the two equations. This is not essential in this study. In addition, considering two different Wiener processes with given correlation would complicate tremendously the algebra (in Section 4) without adding too much economic insight.
} 
the one characterizing the evolution of $R$ :

$$
d R=[(\alpha-e) R+e a p] d t+\sigma_{p} R d W
$$

Now making a change of variable with $\eta=e a p, \xi=\alpha-e$, and $\sigma_{R}=\sigma_{p}$ is enough to retrieve equation (2), given the specification in (3). Taking $a=0$, which implies $\eta=0$, brings us to the analysis of the case of a non-renewable resource like oil, which is the relevant one for describing the Algerian economy. In this case, the sign of $\xi$ basically depends on the relative size of $\alpha$ and $e$. Considering $\alpha>e$ means that price increases exceed the decreasing trend of extraction rates and result in ever growing resources rents, whereas when $\alpha<e$ resources revenues are driven down since the fall in extraction dominates the upward tendency of the price. The case with $a>0$ (and furthermore $\eta$ constant) is a very simple representation of the evolution of rents from a renewable resource. However, we keep considering this case to be as general as possible.

Let us now turn to the definition of players' payoffs. Players maximize the present value of benefit from their efforts of liberalization minus the associated cost:

$$
\max _{x_{i}} \int_{0}^{\infty} e^{-r t}\left[\omega_{i}(z)-\beta\left(x_{i}\right)\right] d t
$$

with $r>0$ the (same) rate of time preference, subject to state constraints (1) and (2), with $z(0)=z_{0}$ and $R(0)=R_{0}$ given. Still motivated by our will to keep things as simple as possible, players' instantaneous benefit, $\omega_{i}(z)$, from the level of legislation or liberalization, takes a quadratic form: $\omega_{i}(z)=a_{0} \pm a_{1} z+\frac{a_{2}}{2} z^{2}$, with $a_{0}, a_{1}>0$, and $a_{2} \leq 0$. The opposite sign of the term in $z$ reflects players' opposite interests with respect to the legislation. By convention, player 1 payoff is increasing in $z$, i.e, we put a + in front of $a_{1}$. Moreover, exerting lobbying is a costly activity and we shall use a quadratic lobbying cost: $\beta\left(x_{i}\right)=\frac{b}{2} x_{i}^{2}$. Last but not least, notice that $R$ does not affect the payoff functions directly. Corruption motives or office rents, which would imply that part of the revenue is captured by player 2 shows in her payoff, are left aside. This allows to focus on a game where the players are entirely devoted to push the legislation in the direction they wish, which is the essence of lobbying.

The model above entails two types of uncertainties: one affecting the legislation 
state, $z$, say the legislative uncertainty, and the other resulting from resource revenues volatility. These uncertainties are closely connected. So we cannot do without one of them when examining the outcome of the stochastic game of lobbying. However, due to the quite complex structure of this game, that encompasses two state variables and nonlinear state functions, we have to resort to another simplification if we want to make the problem solvable. Actually, in Section 3, we set the coefficient $a_{2}$ to zero in the payoff functions, thus removing the quadratic term in $z$ from these functions. Though the resulting equilibrium is particular, ${ }^{5}$ the theoretical analysis will allow us to derive clear-cut results regarding the impact of resource revenue volatility on liberalization. In other words, studying the simplified model will be enough to rise the main point that will be then subject to an empirical investigation in Section 4 .

\section{Institutional dynamics under uncertainty: a theoretical investigation}

Our aim is to provide a comprehensive analysis of the stochastic game of lobbying. The analysis will mainly consist in characterizing the Markov Perfect equilibrium (MPE) of the game, and comparing this equilibrium with its deterministic counterpart. In order to emphasize the impact of uncertainty, particular attention will be paid to the long run behavior of the solutions and their respective stability properties. We will finally end this section by a discussion on the implications of the results for the dynamics of institutions. All the proofs are relegated in the Appendix.

\subsection{Stochastic vs deterministic MPE}

We start by solving for the MPE and obtain the following result (see the Appendix A.1):

Proposition 3.1. Under legislative and resource revenue uncertainties, there exists a unique MPE. Players' lobbying efforts are defined by linear feedback rules:

$$
x_{1}(t)=\frac{a_{1}}{b r}, \quad x_{2}(t)=\frac{a_{1}(1+\varepsilon R(t))}{b r} .
$$

\footnotetext{
${ }^{5}$ In fact, as it will be apparent soon, taking $a_{2}=0$ is a mean to neutralize the effect of $z$ - and thus to isolate the specific effect of $R$ - on the equilibrium.
} 
The resulting canonical dynamical system is given by

$$
\left\{\begin{array}{l}
d z=-\frac{a_{1} \varepsilon}{b r}(2+\varepsilon R) R d t+\sigma_{z} z d W \\
d R=(\eta+\xi R) d t+\sigma_{R} R d W
\end{array}\right.
$$

Thus player 1's equilibrium effort is constant while player 2's effort linearly depends on the resource rent $R$. More precisely, one can observe that equilibrium strategies are independent of the legislative state, $z$. Given the exogenous nature of the dynamics of $R$, this implies that MPE strategies ultimately form dominant strategies. This comes from zeroing $a_{2}$ in the payoff functions. This case may seem to be extremely particular. Still, it is most useful as it allows us to emphasize the pure impact of resource revenues on the lobbying game: Player 1 , which is by assumption not directly affected by these windfalls, has a constant feedback, whereas player 2 does care about resource revenue because they increase her lobbying power. Then it appears that player 2's lobbying effort goes up as the economy gets more revenue from natural resources.

In order to highlight the dynamic and asymptotic implications of resource revenue volatility, we solve for the canonical system (6) to obtain the MPE expressions of $z$ and $R$ at any instant $t$ :

$$
\begin{aligned}
& R(t)=e^{\left(\xi-\frac{\sigma_{R}^{2}}{2}\right) t+\sigma_{R} W_{t}}\left[R_{0}+\eta \int_{0}^{t} e^{-\left(\xi-\frac{\sigma_{R}^{2}}{2}\right) s-\sigma_{R} W_{s}} d s\right] \\
& z(t)=e^{-\frac{\sigma_{z}^{2}}{2} t+\sigma_{z} W_{t}}\left[z_{0}+\int_{0}^{t} A(s) e^{\frac{\sigma_{z}^{2}}{2} s-\sigma_{z} W_{s}} d s\right]
\end{aligned}
$$

with $A(t)=-\frac{a_{1} \varepsilon}{b r}(2+\varepsilon R(t)) R(t)$.

Let us start with a quick investigation of the deterministic MPE, which we use as a benchmark. Then we will examine the stability properties of the stochastic MPE and bring out some conclusions on how the volatility of resource revenue affects the outcomes of the lobbying game asymptotically. Note that from (6), it is clear that the stability analysis can be performed sequentially, studying the stability of $R(t)$ first, then moving to the one of $z(t)$. 
First, assuming that $\sigma_{R}=\sigma_{z}=0$, we can establish that: ${ }^{6}$

Proposition 3.2. Suppose that $\eta \geq 0$. Then the deterministic MPE may exhibit the following asymptotic properties:

(2.a) If $\xi>0$ and $\eta \geq 0$, we have $\lim _{t \rightarrow \infty} R(t)=+\infty$ and $\lim _{t \rightarrow \infty} z(t)=-\infty$.

(2.b) If $\xi<0$ and $\eta>0$, we have $\lim _{t \rightarrow \infty} R(t)=-\frac{\eta}{\xi}$ and $\lim _{t \rightarrow \infty} z(t)=-\infty$.

(2.c) If $\xi<0$ and $\eta=0$, we have $\lim _{t \rightarrow \infty} R(t)=0$ while

$$
\lim _{t \rightarrow \infty} z(t)=\frac{a_{1} \varepsilon R_{0}}{b r \xi}+\frac{a_{1} \varepsilon^{2} R_{0}^{2}}{2 b r \xi}<0 .
$$

Not surprisingly, given the shape of the equilibrium strategies displayed in Proposition 3.1, the deterministic game yields an explosive steady state as the legislative state $z$ goes to $\infty$, with the exception of the parametric case $\eta=0$ and $\xi<0$. Even in the case where resource revenues are finite asymptotically $(\eta>0$ and $\xi<0$ ), the system leads to an economy which is infinitely conservative. Only in the case where the resource rents vanish in the long-run, that is the case $\eta=0$ and $\xi<0$, the economy can converge to a steady state, thereby implying that the corresponding costs of lobbying get limited asymptotically.

As mentioned in Section 2, the cases with $\eta=0$ and $\xi \lessgtr 0$ describe the dynamic behavior of an economy that relies on non-renewable resources rents like oil. For this kind of economy, we observe that both situations are possible. In particular, the economy will reach in the long run a steady state with finite $R$ and $z$ if and only if the effect of decreasing extraction rates exceeds the positive trend of the resource price (case 2.c). ${ }^{7}$ Otherwise, resource wealth goes to $+\infty$, which in turn brings the level of legislation to $-\infty$ (case 2. $a$ with $\eta=0$ ). Finally, the cases with $\eta>0$ and $\xi \lessgtr 0$ better represent economies that own and sell renewable resources. In these cases, regardless

${ }^{6}$ The solutions in $(7)$ reduce to

$$
\begin{aligned}
& R(t)=\left(R_{0}+\frac{\eta}{\xi}\right) e^{\xi t}-\frac{\eta}{\xi}, \\
& z(t)=-\frac{a_{1} \varepsilon}{b r}\left[\left(R_{0}+\frac{\eta}{\xi}\right) \frac{e^{\xi t}-1}{\xi}-\frac{\eta}{\xi} t\right]-\frac{a_{1} \varepsilon^{2}}{b r}\left[\left(R_{0}+\frac{\eta}{\xi}\right)^{2} \frac{e^{2 \xi t}-1}{2 \xi}+\frac{\eta^{2}}{\xi^{2}} t-\left(R_{0}+\frac{\eta}{\xi}\right) \frac{2 \eta\left(e^{\xi t}-1\right)}{\xi^{2}}\right] .
\end{aligned}
$$

${ }^{7}$ Actually, in this case, the resource will be exhausted asymptotically. 
of the level to which resource rents converge, the economy ends up in an infinitely conservative system, with $z=-\infty$, which implies ever increasing costs of lobbying. It's worth pointing out that if players' lobbying powers were equal, one would get the Wirl's result: the economy converges to the center of the political spectrum. If instead we assume as in this section that the proponents of the conservative line get their bargaining position improved when the resource revenues go up as in Algeria, we get conservative political states asymptotically, which is fully consistent with Friedman's first law of petropolitics.

Next, the important question is: Could uncertainty, by acting as a stabilization mechanism, change the general conclusion drawn from the analysis of the benchmark? Before answering this question, it proves useful to define what is meant by stochastic stability:

Definition 1. A stochastic process $y(t)$ is stable if there is stationary time invariant distribution of $y(t)$ for $t \rightarrow \infty .^{8}$

According to (1), which is borrowed from Merton (1975), the $y$-process is said to be (asymptotically) stable if and only if there is a unique distribution which is time and initial condition independent, and toward which the stochastic process tends.

With this definition in mind, we can prove that (see the Appendix A.2):

Proposition 3.3. Suppose that the level of volatility in the $R$-process is high enough and satisfies

$$
\left.\sigma_{R}>\underline{\sigma}_{R} \text { with } \underline{\sigma}_{R}=\sqrt{(} 2 \xi\right)
$$

and $\sigma_{z}>0$. Then, both $R$ and $z$ will converge in the long-run to a stationary distribution which is time invariant and independent of the initial conditions.

(1) First suppose that $\eta>0$. The stochastic processes' density are given by

$$
\begin{aligned}
& \pi_{z}(z, R)=\frac{m}{\sigma_{z}^{2} z^{2}} \exp \left\{-\frac{2 a_{1} \varepsilon R(2+\varepsilon R)}{b r \sigma_{z}^{2}} \frac{1}{z}\right\} \\
& \pi_{R}(R ; \eta)=\frac{n R^{\frac{2 \xi}{\sigma_{R}^{2}}}}{\sigma_{R}^{2} R^{2}} \exp \left\{-\frac{2 \eta}{\sigma_{R}^{2} R}\right\}
\end{aligned}
$$

\footnotetext{
${ }^{8}$ If this density distribution degenerates into a Dirac function, then the stochastic process converges to a unique point.
} 
where $\pi_{z}(z, R)$ represents the density of $z$ conditional on $R$. Parameters $m, n>0$ are chosen such that $\int_{-\infty}^{+\infty} \pi_{z}(z, R) d z=1$, and $\int_{0}^{+\infty} \pi_{R}(R ; \eta) d R=1$.

(2) Second, consider that $\eta=0$. Both stochastic processes $R$ and $z$ converge to a steady state $\left(R_{\infty}, z_{\infty}\right)$ with

$$
R_{\infty}=z_{\infty}=0
$$

We can now put all of these elements together to draw a first series of policy implications from our analytical results. The impact of legislative uncertainty and resource revenue volatility mostly show up in the long run properties of the MPE. More precisely, the comparison between Propositions 3.2 and 3.3 clearly highlights the stabilization power of uncertainty. First, when the deterministic MPE is stable (case 2.c), we obtain that the stochastic MPE is necessarily stable as well. More importantly, when the conditions are such that the deterministic economy follows an explosive path (at least in terms of $z$, cases 2.a \& 2.b), a sufficient level of uncertainty in the $R$-process, as defined by (9), ensures that the stochastic system will reach a stationary state in the long run, that is characterized by the density functions in Proposition 3.3.

As far as policy implications are concerned, let us focus first on case 2.c. Here we observe that besides stabilization, uncertainties endow the economy with better institutions in the long run. Therefore, our results tend to weaken the case for the resource curse hypothesis (Ross, 2001) and for the first law of geopolitics advocated by Frieman. Resource wealth might lead to inefficient institutions (this is the sense of our results in the deterministic case). But, what ultimately matters is not the level of wealth but its volatility. Once we account for such volatility, we obtain that resource wealth may in fact improve the institutions (at least when $z_{0}<0$ ), which is apparent from (8) and (11). The same kind of conclusion can be drawn from the analysis of the more general cases 2.a \& 2.b, except that we have now to discuss about long run densities rather than steady states. In these situations, considering the impact of resource rents introduces a bias in the interaction between lobbyists toward the conservatives and necessarily leads, in the long run, to a terribly bad outcome in terms of the legislation, or the institutions, in the deterministic world. This is no longer the case under uncertainty. Again, anything can happen because of the convergence to time invariant and independent of initial states distributions for both $z$ and $R$. But this in particular implies that the economy might achieve a long run equilibrium characterized by a finite and even positive 
state of legislation (with positive probability). We elaborate further on this idea in the next Section.

\subsection{Implications of resource revenues volatility}

Besides the general implications discussed above, we can emphasize a more direct and thus testable link between volatility and the level of liberalization. Indeed, investigating the properties of the density functions displayed in Proposition 3.3, we obtain the following:

Corollary 3.4. Under condition (9),

(1) the level $\widehat{R}=\frac{\eta}{\sigma_{R}^{2}-\xi}$, defined by $\frac{d \pi_{R}(R ; \eta)}{d R}=0$, is the most likely position of resource revenue in the long-run.

(2) For any windfall level, $\widehat{z}(R)=\frac{a_{1} \varepsilon R(2+\varepsilon R)}{b r \sigma_{z}^{2}}$, such that $\frac{d \pi_{z}(z)}{d z}=0$, is the most likely position of the state of liberalization. In addition, we have $\widehat{z}(R)=0$ if and only if $R=0$.

(3) The most likely position $\widehat{z}(\widehat{R})$ is decreasing in $\sigma_{R}$.

So, we immediately note that if a sufficient level of volatility is needed for promoting liberalization, too much volatility is actually bad news for the reformists. Other things equal, an increase in $\sigma_{R}$ implies that (extreme) realizations of the stochastic process $W$ will be felt strongly by the conservatives. In particular, this group will be able to rely on a series of extremely favorable realizations of $w$ (think about a long period of consecutive rises in resource prices) to establish and reinforce their dominating position in the political and economic arenas. This is simply a consequence of their lobbying efforts being responsive to the level and therefore the variations of $R$. As a result, a higher $\sigma_{R}$ is very likely to be associated with a more conservative position in the long term. This is basically the message conveyed by the third item of Corollary 3.4: the larger the volatility as it is captured by $\sigma_{R}$, the lower the (most likely) level of liberalization in the long run. 


\section{Economic liberalization under volatile natural resource revenues: empirical investigation}

\subsection{Model and Data}

In this section, we test the main prediction of our theoretical framework. The prediction is the higher the resources revenues volatility is the less the probability to be liberalization changes in the economy. Below, we analyze our empirical specification, the data we used to estimate it and then we describe our results.

\subsubsection{Empirical model}

Our main specification is based on Abiad and Mody (2005) and it is the following one:

$$
\begin{gathered}
\Delta F L_{i t}=\theta_{1} F L_{i t-1}\left(1-F L_{i t-1}\right)+\theta_{2} \text { Resourcevolatility }_{i t}+ \\
\theta_{3} \text { shocks }_{i t}+\theta_{4} \text { ideology }_{i t}+\theta_{5} \text { structure }_{i t}+\theta_{6}\left(R E G F L_{i t-1}-F L_{i t-1}\right)+e_{i t}
\end{gathered}
$$

We use ordered probit method for our estimation of the Equation (15) given the discrete and ordinal nature of the dependent variable. The $F L_{i t}$ is the financial liberalization index. The dependent variable of Equ. (15) is $\Delta F L_{i t}$, which measures policy changes. The main independent variable of interest is the Resourcevolatility ${ }_{i t}$. According to our model prediction, we expect that $\theta_{2}$ will be negative. In our the words, the larger the volatility of the revenues of natural resources, the less the probability to be liberal. Moreover, we include a number of additional controls. The variable of $F L_{i t-1}\left(1-F L_{i t-1}\right)$ allows us to capture possible domestic "learning". More precisely, the $\theta_{1}$ captures the status quo bias. We expect that it will be greater than 0 . The presumption is that the status quo bias is highest when financial sectors are repressed and the bias declines as the sector liberalizes. ${ }^{9}$ We also include the possibility of regional diffusion with the variable $\left(R E G F L_{i t-1}-F L_{i t-1}\right)$. It is important countries within a region would be prompted to catch up with the highest level of liberalization reached within the region either due to a reduction in uncertainty regarding the benefits of reform or due to competition for external capital flows.

\footnotetext{
${ }^{9}$ For instance, in a multiple stage version of the Fernandez-Rodrik Model where earlier reforms are responsible to identify winners and losers.
} 
We use a number of variables in the category shocks $s_{i t}$. In particular, we include dummy variables capturing Banking crises, currency crises and inflation crises. We also use political variables in the ideology $y_{i t}$ category. More precisely, we test the honeymoon hypothesis by including a dummy highlighting the the incumbent executive's first year office. Also, we incorporate variable that captures the political orientation to reform like dummy variables for left-wing and right-wing governments. ${ }^{10}$ As it concerns the structure variables, we include trade openness.

We alternate our specification such as to relax potential assumptions that related to the speed of adjustment to the desired level of liberalization that they are captured through the variable $F L_{i t-1}\left(1-F L_{i t-1}\right) \cdot{ }^{11}$ In other words, we substitute the variable $F L_{i t-1}\left(1-F L_{i t-1}\right)$ with $F L_{i t-1}$ and $F L_{i t-1}^{2}$. Now, the different model has the following specification:

$$
\begin{gathered}
\Delta F L_{i t}=\theta_{1} F L_{i t-1}+\theta_{2} F L_{i t-1}^{2}+\theta_{3} \text { Resourcevolatility }{ }_{i t}+ \\
\theta_{4} \text { shocks }_{i t}+\theta_{5} \text { ideology }_{i t}+\theta_{6} \text { structure }_{i t}+\theta_{7}\left(R E G F L_{i t-1}-F L_{i t-1}\right)+e_{i t}
\end{gathered}
$$

where $\theta_{1}$ and $\theta_{2}$ are expected to be positive and negative respectively.

To take into account potential simultaneous determination between the changes of financial liberalization index and resources' revenues volatility, we apply a joint maximum likelihood estimation.

The model is formed as a system of equations

$$
\begin{gathered}
\Delta F L_{i t}=\theta_{1} F L_{i t-1}\left(1-F L_{i t-1}\right)+\theta_{2} \text { Resourcevolatility }_{i t}+ \\
\theta_{3} \text { shocks }_{i t}+\theta_{4} \text { ideology }_{i t}+\theta_{5} \text { structure }_{i t}+\theta_{6}\left(R E G F L_{i t-1}-F L_{i t-1}\right)+\lambda \zeta_{i}+\eta_{i t}
\end{gathered}
$$

$$
\text { Resourcevolatility }_{i t}=\beta_{1} F L_{i t-1}\left(1-F L_{i t-1}\right)+\beta_{2} X_{i, t}
$$$$
\beta_{3} \text { shocks }_{i t}+\beta_{4} \text { ideology }_{i t}+\beta_{5} \text { structure }_{i t}+\beta_{6}\left(\text { REGF } L_{i t-1}-F L_{i t-1}\right)+\zeta_{i}+\omega_{i t}
$$

where $X_{i, t}$ is a variable used to be able to identify the system of the two equations. Also, $\zeta_{i}$ is a latent variable inducing dependence between $u_{1 i t}=\lambda \zeta_{i}+\eta_{i t}, u_{2 i t}=\zeta_{i}+\omega_{i t}$

\footnotetext{
${ }^{10}$ The centrist governments are the omitted category.

${ }^{11}$ Abiad and Moody (2005) discuss on the detail the assumptions related to this variable. They use similar specification to relax this assumption.
} 
and $\lambda$ is a loading factor (free parameter)- see Miranda and Rabe-Hesketh (2006). The reduced form does not include dynamics. Assuming a bivariate normal distribution for $\left(u_{1 i t}, u_{2 i t}\right)$ given that $\left(\zeta_{i}, \eta_{i t}, \omega_{i t}\right)$ are $\operatorname{iidN}(0,1)$, the respective residual covariance matrix $\Omega$ corresponds to

$$
\Omega \equiv \operatorname{Cov}\left[\left(u_{1 i t}, u_{2 i t}\right)^{\prime}\right]=\left(\begin{array}{cc}
\lambda^{2}+1 & \lambda \\
\lambda & 2
\end{array}\right)
$$

giving a correlation coefficient

$$
\rho=\frac{\lambda}{\sqrt{2\left(\lambda^{2}+1\right)}} .
$$

\subsubsection{Data}

The study draws up on a panel dataset combining financial liberalization index, resources revenues volatility, political, shocks and structure variables. Our financial liberalization index is collected from the new database Abiad et al. (2008) and covers 91 economies over the period 1973-2005. ${ }^{12}$ It is the aggregated measure of eight financial reform dimensi! ons:1) credit controls and excessively high reserve requirements, 2) aggregate Credit Ceilings 3)interest rate liberalization, 4) entry barriers in the banking sector,5) privatization in the financial sector, 6) securities market reforms, 7)Banking supervision 8) Capital account transactions. Along each dimension, a country is given a final score on a graded scale from 0 to 3 , with 0 corresponding to the highest degree of repression and 3 indicating full liberalization. Thereby, the overall measure takes on integer values between 0 and 24. To facilitate interpretation of the regressions, we divide the overall liberalization index by 24 such as to be ranged from 0 to 1 , with 0 corresponding to a completely repressed financial sector and 1 corresponding to fully

\footnotetext{
${ }^{12}$ Albania, Ecuador, Kenya, Russia, Algeria, Egypt, Korea, Senegal, Argentina, El Salvador, Kyrgyz Republic, Singapore, Australia, Estonia, Latvia, South Africa, Austria Ethiopia Lithuania, Spain, Azerbaijan, Finland, Madagascar, Sri Lanka, Bangladesh, France, Malaysia, Sweden, Belarus, Georgia, Mexico, Switzerland, Belgium, Germany, Morocco, Taiwan, Bolivia, Ghana, Mozambique, Tanzania, Brazil, Greece, Nepal, Thailand, Bulgaria, Guatemala, Netherlands, Tunisia, Burkina-Faso, Hong Kong, New Zealand Turkey, Cameroon, Hungary, Nicaragua, Uganda, Canada, India Nigeria Ukraine, Chile, Indonesia, Norway, United Kingdom, China, Ireland, Pakistan, United States, Colombia, Israel, Paraguay, Uruguay, Costa Rica, Italy, Peru, Uzbekistan, Cote d'Ivoire, Jamaica Philippines, Venezuela, Czech Republic Japan, Poland, Vietnam, Denmark, Jordan, Portugal, Zimbabwe, Dominican Republic, Kazakhstan, Romania
} 
liberalized financial sector.

We have two variables to measure and construct the resource revenue volatility. The first and main variable is the oil rent. The ASPO dataset provides information on oil price and oil production for most oil countries since 1930. Public data such as the BP dataset also contains production data since 1965. Finally, cost data are obtained from the World Bank Genuine Savings database. Since the cost data are available only after 1970 and for many countries the cost time series is imputed based on just a few observations, we compute for each country an average cost and apply this average cost throughout the sample period which is from 1975 to 2005. The second variable is the percentage of revenues from the natural resources collected from World Bank indicator and we multiply this variable with the income per capital taken from the World Bank indicators to construct the total revenue of natural resources. The second variable is used for robustness of our main results. We construct the cyclical resources revenues volatility in a given year and country as the standard deviation of a centered 4-year window of de-trended oil rents or natural resources. This method has become somewhat standard; see Jaimovich and Siu (2009). We apply the Hodrick-Prescott (HP) filter with smoothing parameter 6.25 to the entire series. Finally, we calculate the standard deviation of the 4-year rolling windows of the deviations from trend. The entire process is done separately for each country. ${ }^{13}$

Data for political variables are collected from World Bank Political Institutions. The availability of the sample of the above variables is from 1975 to 2015 but we use until 2005 given the last year of the financial liberalization index is 2005. The political variables used are defined as follows. The first year in office dummy is based on YRSOFFC which describes "How many years has the chief executive been in office". Using the variable EXECRLC we obtain the political orientation variables left-wing party, rightwing and center. The database designates party orientation based on the presence of certain terms in the party name and description. Those described as as conservative, Christian democratic, or right-wing are classified in one group named Right. Those named as centrist are the second group ( the base in our regressions)and those defined as as communist, socialist, social democratic, or left -wing as left.

The crises variables are collected from Reinhart and Rogoff (2011).This database of-

\footnotetext{
${ }^{13}$ We have calculate the volatility under different year rolling windows to provide robustness of our analysis.
} 
fers different dummy variables crises like inflation and hyperinflation crises, currency crises which include balance-payment crises and banking crises. The time span of the variables is from 1890 to 2011. We restrict our sample from 1975 to 2005 and only to 91 countries as the limitation is because of financial liberalization index. At the end, trade openness is collected from World Bank Indicators.

\subsection{Results}

This Section analyses the baseline CRE ordered probit model estimates and, the joint MLE results accounting for simultaneous determination of financial liberalization index and resource revenue volatility. We then present robustness checks for our main hypothesis using CRE ordered probit specifications. ${ }^{14}$

Table 1 presents the estimation results of the key determinants of financial liberalization index. Columns 1 to 2 and Columns 3 and 4 show the estimation results of Eq.(15) and Eq.(16) for 91 countries over the sample period 1975-2005 respectively. Moreover, columns 5 and 6 report the results of Eq.(15) splitting the sample in advanced and developing countries. The division of the sample in developing and advanced countries have been based on the World Bank distinction according to their income.

The main variable of interest in all the regressions is the resources revenue volatility. All the columns show that the coefficient of the variable has a negative sign and it is significant at $5 \%$. In other words, we find that as the resources revenues volatility increases it is less likely to become liberal. This result is consistent with the main prediction of our theoretical framework. As we can see, this result remains robust across different specifications and sample distinctions.

The rest results are as follows.Columns 1, 2, 5 and 6 report that the coefficients of the domestic learning $F L(t-1) *(1-F L(t-1))$ and the regional diffusion variable $R E G_{F} L_{i, t-1}-F L_{i, t-1}$ have a positive and significant coefficient at 1-percent level the hypothesis that status quo bias decreases as financial liberalization increases. Columns 3 and 4 confirm the above relationship given that we find evidence of U-shaped relationship between the policy/liberalization change and the level of liberalization.

Columns 2, 4, 5 and 6 of table 1 include additional control variables. The coeffi-

\footnotetext{
${ }^{14}$ In the appendix, we estimate our models using ordered logit. The results remain robust.
} 
cient on the crisis dummy variable is negative and statistical significant at 10-percent level only in Columns 2 and 5 suggesting that it is less like to be financially liberal the countries once there are currency crises. It is worth it to highlight it that column 5 presents the results of Eq.(15) for the advanced income countries. In contrast, we find that the banking crises' coefficient is not significant and it has a positive sign. Similar, we find that the inflation crises coefficient is positive and it is significant at 5-percent level only in the Columns 2 and 4. Thus, potential less government controls of the financial sectors appears to be a temporary response to inflation crises.

The coefficient on the dummy variable for first year in office is positive but not significant (see columns 2, 4 and 5). The sign of this coefficient changes in column 6 but it remains not significant. Finally, the left wing dummy variable has smaller coefficient than the right-wing dummy variable. This indicates that the right governments is more likely to liberalize the financial sector of their countries. The coefficient of both variables is significant and positive in Columns 2, 4 and 5. On the other hand, their coefficient changes sign and it is not any more significant as it concerns the developing countries sample. Last, a country's openness to trade variable as measured by the sum of imports and exports relative to GDP, is not significant in none of the Columns of Table 1. 
Table 1: Ordered Probit Estimates

\begin{tabular}{|c|c|c|c|c|c|c|}
\hline & $\begin{array}{c}(1) \\
\Delta F L_{i t}\end{array}$ & $\begin{array}{c}(2) \\
\Delta F L_{i t}\end{array}$ & $\begin{array}{c}(3) \\
\Delta F L_{i t}\end{array}$ & $\begin{array}{c}(4) \\
\Delta F L_{i t}\end{array}$ & $\begin{array}{c}(5) \\
\Delta F L_{i t}\end{array}$ & $\begin{array}{c}(6) \\
\Delta F L_{i t}\end{array}$ \\
\hline$F L(t-1) *(1-F L(t-1))$ & $\begin{array}{c}3.5942^{* * * *} \\
(0.4189)\end{array}$ & $\begin{array}{c}3.1384^{* * * *} \\
(0.4786)\end{array}$ & & & $\begin{array}{c}4.8837^{* * * *} \\
(0.6350)\end{array}$ & $\begin{array}{c}4.7081^{* * * *} \\
(1.3941)\end{array}$ \\
\hline$R E G_{F} L_{i, t-1}-F L_{i, t-1}$ & $\begin{array}{c}2.1802^{* * *} \\
(0.2291)\end{array}$ & $\begin{array}{c}2.1578^{* * *} \\
(0.2565)\end{array}$ & $\begin{array}{c}2.4219^{* * *} \\
(0.3483)\end{array}$ & $\begin{array}{c}3.7952^{* * *} \\
(0.7629)\end{array}$ & $\begin{array}{c}3.3563^{* * *} \\
(0.3409)\end{array}$ & $\begin{array}{c}0.4993 \\
(0.6692)\end{array}$ \\
\hline RESOURCE $E_{V} O L A T I L I T Y_{i, t}$ & $\begin{array}{c}-0.0083^{* *} \\
(0.0038)\end{array}$ & $\begin{array}{c}-0.0097^{* *} \\
(0.0039)\end{array}$ & $\begin{array}{c}-0.0089^{* *} \\
(0.0038)\end{array}$ & $\begin{array}{c}-0.0175^{* *} \\
(0.0069)\end{array}$ & $\begin{array}{c}-0.0094^{* *} \\
(0.0052)\end{array}$ & $\begin{array}{c}-0.0132^{* *} \\
(0.0060)\end{array}$ \\
\hline$R I G H T_{i, t}$ & & $\begin{array}{c}0.3534^{* * *} \\
(0.1083)\end{array}$ & & $\begin{array}{c}0.7362^{* * *} \\
(0.2024)\end{array}$ & $\begin{array}{c}0.3795^{* * *} \\
(0.1194)\end{array}$ & $\begin{array}{c}-0.0652 \\
(0.2635)\end{array}$ \\
\hline FIRSTYEAR $R_{i, t}$ & & $\begin{array}{c}0.0430 \\
(0.0749)\end{array}$ & & $\begin{array}{c}0.1123 \\
(0.1386)\end{array}$ & $\begin{array}{c}0.1039 \\
(0.0917)\end{array}$ & $\begin{array}{l}-0.0586 \\
(0.1396)\end{array}$ \\
\hline CURRENCY $Y_{i, t}$ & & $\begin{array}{c}-0.1587^{*} \\
(0.0872)\end{array}$ & & $\begin{array}{l}-0.2061 \\
(0.1661)\end{array}$ & $\begin{array}{c}-0.1825^{*} \\
(0.1031)\end{array}$ & $\begin{array}{c}-0.1585 \\
(0.1802)\end{array}$ \\
\hline$O P E N_{i, t}$ & & $\begin{array}{l}-0.0383 \\
(0.0589)\end{array}$ & & $\begin{array}{l}-0.1031 \\
(0.1121)\end{array}$ & $\begin{array}{l}-0.0124 \\
(0.0642)\end{array}$ & $\begin{array}{l}-0.1577 \\
(0.1564)\end{array}$ \\
\hline$L E F T_{i, t}$ & & $\begin{array}{l}0.2533^{* *} \\
(0.1126)\end{array}$ & & $\begin{array}{c}0.5534^{* * *} \\
(0.2088)\end{array}$ & $\begin{array}{l}0.2182^{*} \\
(0.1292)\end{array}$ & $\begin{array}{c}-0.1348 \\
(0.2674)\end{array}$ \\
\hline$B A N K_{i, t}$ & & $\begin{array}{c}0.1307 \\
(0.0828)\end{array}$ & & $\begin{array}{l}0.3173^{* *} \\
(0.1537)\end{array}$ & $\begin{array}{c}0.0384 \\
(0.0951)\end{array}$ & $\begin{array}{c}0.1232 \\
(0.1807)\end{array}$ \\
\hline$I N F L A T I O N_{i, t}$ & & $\begin{array}{l}0.2494^{* *} \\
(0.1180)\end{array}$ & & $\begin{array}{l}0.4664^{* *} \\
(0.2158)\end{array}$ & $\begin{array}{c}0.1410 \\
(0.1220)\end{array}$ & $\begin{array}{c}0.6173 \\
(0.3901)\end{array}$ \\
\hline$F L_{i, t-1}$ & & & $\begin{array}{c}3.7225^{* * *} \\
(0.4283)\end{array}$ & $\begin{array}{c}6.5735^{* * *} \\
(0.9655)\end{array}$ & & \\
\hline$\left(F L_{i, t-1}\right)^{2}$ & & & $\begin{array}{c}-3.5298^{* * *} \\
(0.4300)\end{array}$ & $\begin{array}{c}-6.5444^{* * *} \\
(0.9044) \\
\end{array}$ & & \\
\hline Log-Likelihood & -2777.619 & -2542.489 & -2777.189 & -2528.847 & -1928.586 & -565.706 \\
\hline Sample-Size & 1969 & 1780 & 1969 & 1780 & 1255 & 525 \\
\hline
\end{tabular}

Notes: ${ }^{* * *}, * *$, and ${ }^{*}$ indicate statistical significance at the $1 \%, 5 \%$ and $10 \%$ levels respectively. Standard Errors are adjusted for country level clustering.

In section 4.1.1, we discussed that we take into account possible simultaneity of resources revenue volatility and financial liberalization index. Table 2 reports the results of the joint-MLE estimation of the Eq.(17) and Eq.(18). Columns 1 and 2 report the results of joint-MLE of the Eq.(17) and Eq(18). Columns 3 and 4 illustrates the results of joint-MLE substituting the domestic learning variable, $F L(t-1) *(1-F L(t-1))$ in both equations with the financial liberalization index $F L(t-1)$ and its square term $F L(t-1)^{2}$. To identify the system of the two equations, we use an additional variable in Eq.(18) as an instrument. In Columns 1 and 3, we use the oilreserves. The idea of using oilreserves is inspired from see Alexeev and Conrad, 2009 and Tsui (2011) that instrument the oil rents with oilreserves. In Columns 2 and 4, we use the lagged value of resource revenue volatility.

We notice in Table 2 that the coefficient of resource revenue volatility is negative and highly significant in all the columns. Similarly to Table 1 , we find that the variables left- 
wing and right- wing governments are significant. The same happens for the domestic learning and regional diffusion variables. As it concerns the shock variables Bank, currency and inflation dummy crises they have similar signs as in Table 1. The currency and inflation dummy crises remain significant and on the contrary the coefficient of bank crises dummy variable is not significant.

Moreover, the Error-Correlation is not significant in all the columns of Table 2. This result indicates that there is not evidence of simultaneity between the resource revenues volatility and financial liberalization. As a consequence, the estimations of order probit are preferable from those of joint-MLE. 
Table 2: Joint Likelihood estimation Estimates probit

\begin{tabular}{|c|c|c|c|c|}
\hline & $\begin{array}{c}(1) \\
\Delta F L_{i t}\end{array}$ & $\begin{array}{c}(2) \\
\Delta F L_{i t}\end{array}$ & $\begin{array}{c}(3) \\
\Delta F L_{i t}\end{array}$ & 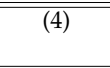 \\
\hline $\begin{array}{l}\Delta F L_{i t} \\
F L(t-1) *(1-F L(t-1))\end{array}$ & $\begin{array}{c}2.0199^{* * *} \\
(0.3025)\end{array}$ & $\begin{array}{c}2.0088^{* * *} \\
(0.3024)\end{array}$ & & \\
\hline$R E S O U R C E_{V} O L A T I L I T Y_{i, t}$ & $\begin{array}{c}-0.0097^{* * *} \\
(0.0035)\end{array}$ & $\begin{array}{c}-0.0084^{* *} \\
(0.0034)\end{array}$ & $\begin{array}{l}-0.0095^{* * *} \\
(0.0035)\end{array}$ & $\begin{array}{c}-0.0085^{* *} \\
(0.0034)\end{array}$ \\
\hline$R I G H T_{i, t}$ & $\begin{array}{c}0.2232^{* * *} \\
(0.0590)\end{array}$ & $\begin{array}{l}0.2229^{* * *} \\
(0.0592)\end{array}$ & $\begin{array}{c}0.2336^{* * *} \\
(0.0612)\end{array}$ & $\begin{array}{c}0.2333^{* * *} \\
(0.0616)\end{array}$ \\
\hline FIRSTYEAR $R_{i, t}$ & $\begin{array}{c}0.0148 \\
(0.0690)\end{array}$ & $\begin{array}{c}0.0140 \\
(0.0688)\end{array}$ & $\begin{array}{c}0.0200 \\
(0.0688)\end{array}$ & $\begin{array}{c}0.0191 \\
(0.0687)\end{array}$ \\
\hline$C U R R E N C Y_{i, t}$ & $\begin{array}{l}-0.1330^{*} \\
(0.0692)\end{array}$ & $\begin{array}{l}-0.1328^{*} \\
(0.0696)\end{array}$ & $\begin{array}{c}-0.1361^{* *} \\
(0.0688)\end{array}$ & $\begin{array}{c}-0.1365^{* *} \\
(0.0693)\end{array}$ \\
\hline$L E F T_{i, t}$ & $\begin{array}{c}0.1931^{* * *} \\
(0.0617)\end{array}$ & $\begin{array}{c}0.1942^{* * *} \\
(0.0616)\end{array}$ & $\begin{array}{c}0.2000^{* * *} \\
(0.0643)\end{array}$ & $\begin{array}{c}0.2009^{* * *} \\
(0.0641)\end{array}$ \\
\hline$B A N K_{i, t}$ & $\begin{array}{c}0.0829 \\
(0.0673)\end{array}$ & $\begin{array}{c}0.0848 \\
(0.0679)\end{array}$ & $\begin{array}{c}0.0859 \\
(0.0661)\end{array}$ & $\begin{array}{c}0.0872 \\
(0.0666)\end{array}$ \\
\hline INFLATION $N_{i, t}$ & $\begin{array}{c}0.2403^{* * *} \\
(0.0806)\end{array}$ & $\begin{array}{c}0.2392^{* * *} \\
(0.0806)\end{array}$ & $\begin{array}{c}0.2227^{* * *} \\
(0.0820)\end{array}$ & $\begin{array}{c}0.2201^{* * *} \\
(0.0823)\end{array}$ \\
\hline$R E G_{F} L_{i, t-1}-F L_{i, t-1}$ & $\begin{array}{l}0.9822^{* * *} \\
(0.1306)\end{array}$ & $\begin{array}{l}0.9809^{* * *} \\
(0.1299)\end{array}$ & $\begin{array}{c}0.8012^{* * *} \\
(0.2248)\end{array}$ & $\begin{array}{c}0.8032^{* * *} \\
(0.2248)\end{array}$ \\
\hline$O P E N_{i, t}$ & $\begin{array}{l}-0.0075 \\
(0.0248)\end{array}$ & $\begin{array}{l}-0.0081 \\
(0.0247)\end{array}$ & $\begin{array}{l}-0.0039 \\
(0.0250)\end{array}$ & $\begin{array}{l}-0.0043 \\
(0.0249)\end{array}$ \\
\hline$\lambda$ & $\begin{array}{c}0.0096 \\
(0.0118)\end{array}$ & $\begin{array}{c}0.0054 \\
(0.0147)\end{array}$ & $\begin{array}{c}0.0113 \\
(0.0119)\end{array}$ & $\begin{array}{c}0.0083 \\
(0.0157)\end{array}$ \\
\hline$F L_{i, t-1}$ & & & $\begin{array}{l}1.8275^{* * *} \\
(0.3516)\end{array}$ & $\begin{array}{c}1.8178^{* * *} \\
(0.3526)\end{array}$ \\
\hline$F L_{i, t-1}^{2}$ & & & $\begin{array}{l}-2.0018^{* * *} \\
(0.3011)\end{array}$ & $\begin{array}{c}-1.9890^{* * *} \\
(0.3012) \\
\end{array}$ \\
\hline $\begin{array}{l}\text { RESOURCE } E_{V} O L A T I L I T Y_{i, t} \\
\text { OILRESERVES }\end{array}$ & $\begin{array}{l}2.6715^{* *} \\
(1.5199)\end{array}$ & & $\begin{array}{l}2.6720^{* *} \\
(1.5306)\end{array}$ & \\
\hline$F L(t-1) *(1-F L(t-1))$ & $\begin{array}{l}-2.1607^{*} \\
(1.2179)\end{array}$ & $\begin{array}{l}-2.2524 \\
(1.7186)\end{array}$ & & \\
\hline$R E G_{F} L_{i, t-1}-F L_{i, t-1}$ & $\begin{array}{l}-0.8737 \\
(0.5655)\end{array}$ & $\begin{array}{l}-0.9583 \\
(0.6633)\end{array}$ & $\begin{array}{c}0.1919 \\
(0.6658)\end{array}$ & $\begin{array}{c}0.7056 \\
(0.6723)\end{array}$ \\
\hline$R I G H T_{i, t}$ & $\begin{array}{l}-0.0271 \\
(0.2546)\end{array}$ & $\begin{array}{l}-0.0729 \\
(0.3326)\end{array}$ & $\begin{array}{c}-0.0324 \\
(0.2518)\end{array}$ & $\begin{array}{c}-0.0674 \\
(0.3323)\end{array}$ \\
\hline FIRSTYEAR $R_{i, t}$ & $\begin{array}{l}-0.1717 \\
(0.1109)\end{array}$ & $\begin{array}{c}-0.4424^{*} \\
(0.2565)\end{array}$ & $\begin{array}{l}-0.1730 \\
(0.1102)\end{array}$ & $\begin{array}{l}-0.4506^{*} \\
(0.2567)\end{array}$ \\
\hline$C U R R E N C Y_{i, t}$ & $\begin{array}{l}-0.1680 \\
(0.3138)\end{array}$ & $\begin{array}{c}-0.3332^{*} \\
(0.1947)\end{array}$ & $\begin{array}{c}-0.1442 \\
(0.3111)\end{array}$ & $\begin{array}{c}-0.2911 \\
(0.1874)\end{array}$ \\
\hline$L E F T_{i, t}$ & $\begin{array}{l}-0.0839 \\
(0.2373)\end{array}$ & $\begin{array}{l}-0.1333 \\
(0.2824)\end{array}$ & $\begin{array}{l}-0.0961 \\
(0.2354)\end{array}$ & $\begin{array}{l}-0.1525 \\
(0.2790)\end{array}$ \\
\hline$B A N K_{i, t}$ & $\begin{array}{c}0.0306 \\
(0.3257)\end{array}$ & $\begin{array}{c}-0.3861^{* *} \\
(0.1713)\end{array}$ & $\begin{array}{c}0.0344 \\
(0.3244)\end{array}$ & $\begin{array}{c}-0.3729^{* *} \\
(0.1684)\end{array}$ \\
\hline INFLATION $N_{i, t}$ & $\begin{array}{l}-0.1268 \\
(0.3396)\end{array}$ & $\begin{array}{l}-0.7535^{*} \\
(0.4449)\end{array}$ & $\begin{array}{l}-0.0516 \\
(0.3586)\end{array}$ & $\begin{array}{l}-0.6290 \\
(0.4328)\end{array}$ \\
\hline$O P E N_{i, t}$ & $\begin{array}{l}-0.1282 \\
(0.1594)\end{array}$ & $\begin{array}{c}0.0535 \\
(0.1584)\end{array}$ & $\begin{array}{l}-0.1635 \\
(0.1534)\end{array}$ & $\begin{array}{l}-0.0100 \\
(0.1696)\end{array}$ \\
\hline$L A G_{R} E S O U R C E_{V} O L A T I L I T Y_{i, t}$ & & $\begin{array}{l}0.5250^{* *} \\
(0.2489)\end{array}$ & & $\begin{array}{l}0.5244^{* *} \\
(0.2500)\end{array}$ \\
\hline$F L_{i, t-1}$ & & & $\begin{array}{l}-1.4748 \\
(0.9768)\end{array}$ & $\begin{array}{l}-1.0447 \\
(1.5317)\end{array}$ \\
\hline$F L_{i, t-1}^{2}$ & & & $\begin{array}{l}2.3756^{*} \\
(1.3066)\end{array}$ & $\begin{array}{c}2.4259 \\
(1.7765)\end{array}$ \\
\hline Log-Likelihood & -6650.407 & -7578.386 & -6649.198 & -7576.775 \\
\hline Sample-Size & 1780 & 1780 & 1780 & 1780 \\
\hline Error-Correlation & 0.007 & 0.004 & 0.008 & 0.006 \\
\hline
\end{tabular}

Notes: ${ }^{* * *}, * *$, and ${ }^{*}$ indicate statistical significance at the $1 \%, 5 \%$ and $10 \%$ levels respectively. Standard Errors are adjusted for country level clustering. 
Table 3 illustrates a robustness analysis using different measure of resource revenue volatility and time-rolling windows of constructing the current one. Column 1 illustrates the results using natural resource variable to construct its volatility. Column 2 and 3 report the results of Eq. (15) using the current measure of resource revenues volatility (oilrents) under 6 and 9 years time rolling windows. All the columns confirms our main result and hypothesis that as the volatility of resources revenues increases, it is less likely to countries to liberalize their financial sector. The coefficients of domestic learning and regional diffusion are positive and significant in all the estimations. On the other hand, trade openness, first time in the office, the shock variables (except inflation dummy crises) are not significant. 
Table 3: Ordered Probit Estimates-Robustness

\begin{tabular}{|c|c|c|c|}
\hline & $\begin{array}{c}(1) \\
\Delta F L_{i t}\end{array}$ & $\begin{array}{c}(2) \\
\Delta F L_{i t}\end{array}$ & $\begin{array}{c}(3) \\
\Delta F L_{i t}\end{array}$ \\
\hline $\begin{array}{l}\Delta F L_{i t} \\
F L(t-1) *(1-F L(t-1))\end{array}$ & $\begin{array}{c}4.0937^{* * *} \\
(0.5929)\end{array}$ & $\begin{array}{l}3.3514^{* * *} \\
(0.5016)\end{array}$ & $\begin{array}{c}4.0068^{* * *} \\
(0.5836)\end{array}$ \\
\hline$R E G_{F} L_{i, t-1}-F L_{i, t-1}$ & $\begin{array}{c}3.0418^{* * *} \\
(0.3101)\end{array}$ & $\begin{array}{c}2.6254^{* * *} \\
(0.2742)\end{array}$ & $\begin{array}{c}3.0929^{* * *} \\
(0.3084)\end{array}$ \\
\hline$R E S O U R C E_{V} O L A T I L I T Y_{i, t}$ & $\begin{array}{c}-0.3931^{* * *} \\
(0.1298)\end{array}$ & $\begin{array}{c}-0.0109^{* *} \\
(0.0052)\end{array}$ & $\begin{array}{c}-0.0096^{* * *} \\
(0.0025)\end{array}$ \\
\hline$R I G H T_{i, t}$ & $\begin{array}{l}0.2660^{* *} \\
(0.1205)\end{array}$ & $\begin{array}{c}0.3258^{* * *} \\
(0.1115)\end{array}$ & $\begin{array}{l}0.3042^{* *} \\
(0.1219)\end{array}$ \\
\hline$F I R S T Y E A R_{i, t}$ & $\begin{array}{c}0.1070 \\
(0.0803)\end{array}$ & $\begin{array}{c}0.0808 \\
(0.0764)\end{array}$ & $\begin{array}{c}0.1000 \\
(0.0806)\end{array}$ \\
\hline$C U R R E N C Y_{i, t}$ & $\begin{array}{l}-0.1003 \\
(0.0952)\end{array}$ & $\begin{array}{l}-0.1295 \\
(0.0898)\end{array}$ & $\begin{array}{l}-0.1195 \\
(0.0958)\end{array}$ \\
\hline$O P E N_{i, t}$ & $\begin{array}{c}0.0069 \\
(0.0689)\end{array}$ & $\begin{array}{c}0.0064 \\
(0.0614)\end{array}$ & $\begin{array}{c}0.0328 \\
(0.0687)\end{array}$ \\
\hline$L E F T_{i, t}$ & $\begin{array}{c}0.1248 \\
(0.1301)\end{array}$ & $\begin{array}{c}0.1639 \\
(0.1183)\end{array}$ & $\begin{array}{c}0.1121 \\
(0.1312)\end{array}$ \\
\hline$B A N K_{i, t}$ & $\begin{array}{c}0.1309 \\
(0.0917)\end{array}$ & $\begin{array}{c}0.0935 \\
(0.0839)\end{array}$ & $\begin{array}{c}0.1361 \\
(0.0921)\end{array}$ \\
\hline INFLATION $N_{i, t}$ & $\begin{array}{c}0.1831 \\
(0.1394)\end{array}$ & $\begin{array}{l}0.2445^{* *} \\
(0.1239)\end{array}$ & $\begin{array}{c}0.1570 \\
(0.1401)\end{array}$ \\
\hline $\begin{array}{l}\text { Log-Likelihood } \\
\text { Sample-Size }\end{array}$ & $\begin{array}{c}-2142.829 \\
1541\end{array}$ & $\begin{array}{c}-2416.985 \\
1679\end{array}$ & $\begin{array}{c}-2153.872 \\
1528\end{array}$ \\
\hline
\end{tabular}

Notes: ${ }^{* * *},{ }^{* *}$, and ${ }^{*}$ indicate statistical significance at the $1 \%, 5 \%$ and $10 \%$ levels respectively. Standard Errors are adjusted for country level clustering.

\section{Conclusion}

This paper proposes a dynamic analysis of the economic and political liberalization process in resource-dependent countries, motivated by the empirical debate on the role of oil abundance in the (non)-emergence of democracy and associated writings about the so-called petropolitics (Friedman, 2006). For that purpose, Wirl (1994)'s differential game of lobbying is extended in two major directions. The basic structure of Wirl (1994) is retained: We model the interaction between two groups with opposing 
interests with regard to the state of the legislation. When it comes to the analysis of the dynamics of institutions in Arab countries, such as Algeria, two more ingredients, absent from Wirl's analysis, seem to be particularly important. The first ingredient is the uncertainty in the process of liberalization itself. The second one has to do with the crucial role of resource windfalls in economic and political outcomes, which also rises the question of the role of a second source of uncertainty playing through the dynamics of resource rents. Our study precisely aims at investigating the impact of these two uncertainties on the players' strategies, and more generally, on the properties of the equilibrium.

It is assumed that the player who controls resource revenue benefits from this because it increases her relative lobbying power. Moreover, we put the two sources of uncertainty together in the same picture (the second coming from price volatility). Here, the true impact of uncertainty shows itself in the stability property of the equilibrium. Quite interestingly we obtain under a fairly general condition that uncertainties not only tend to stabilize the behavior of the economy (at least) in the long run, but also promote the convergence toward a state of liberalization that is better than its deterministic counterpart. Taking liberalization as a good indicator of the quality of economic and political institutions, this result helps to explain the mixed support for the oil impedes democracy hypothesis: If resource wealth may tend to worsen institutions, what ultimately matters to understand the impact of resource rents on resourcedependent countries is less their level then their volatility. 


\section{References}

[1] Abiad, A., E. Detragiache and T. Tressel (2008). A new database of financial reforms. IMF Working Paper no. 266,Washington, DC.

[2] Abiad, A., and A. Mody (2005). Financial reform: What shakes it? What shapes it? American Economic Review, 95, 66-88.

[3] Alexeev, M. \& R. Conrad. 2009. The Elusive Curse of Oil. Review of Economics and Statistics, vol. 91(3), 586-598.

[4] Becker G. (1983). A theory of competition among pressure groups for political influence. Quarterly Journal of Economics, 98, 371- 400.

[5] Boucekkine R., P. Pintus and B. Zou (2018b). Mean growth and stochastic stability in endogenous growth models. Economics Letters, forthcoming.

[6] Boucekkine, R., F. Prieur and B. Zou (2018a). Symmetric vs asymmetric equilibria and stochastic stability in a dynamic game of legislative lobbying. Discussion Paper 2018-03, CREA, University of Luxembourg.

[7] Boucekkine R., F. Prieur and K. Puzon (2016). On the timing of political regime changes in resource-dependent economies. European Economic Review, 85, 188-207.

[8] Boucekkine R. and R. Bouklia-Hassane (2011). Rente, corruption et violence: vers l'emergence d'un ordre nouveau dans les pays arabes? Regards Economiques, 92.

[9] Caselli A. and A. Tesei (2016). Resource windfalls, political regimes, and political stability. Review of Economics and Statistics, 98, 573-590.

[10] Cox D. A. and H. Miller (1968). The theory of stochastic processes, John Wiley and Sons. New York.

[11] Dockner E., S. Jorgensen, N. Van Long, and G. Sorger (2000). Differential games in economics and management, Cambridge University Press.

[12] Friedman, T. (2006). The first law of petropolitics. Foreign Policy, 154, 28-36.

[13] Gylfason T. (2001). Natural resources, education, and economic development. European Economic Review, 45, 847-859. 
[14] Haber, S. \& V. Menaldo (2011). Do Natural Resources Fuel Authoritarism? A Reappraisal of the Resource Curse. American Political Science Review, 105(1), 1-26.

[15] Jaimovich, N., and H. E. Siu (2009). The Young, the Old, and the Restless: Demographics and Business Cycle Volatility, American Economic Review, 99(3), 804-826.

[16] Krueger A. (1974). The political economy of the rent-seeking society. The American Economic Review, 64, 291-303.

[17] Leininger W. and C-L. Yang (1994). Dynamic rent-seeking games. Games and Economic Behaviour, 7, 406-427.

[18] Merton R. (1975). An asymptotic theory of growth under uncertainty. The Review of Economic Studies, 42(3), 375-393.

[19] Miranda A., and S. Rabe-Hesketh (2006). Maximum likelihood estimation of endogenous switching and sample selection models for binary, ordinal, and count variables. Stata Journal, vol. 6(3), 285-308.

[20] Reinhart, C. and K. Rogoff (2011) From Financial Crash to Debt Crisis. American Economic Review, 101, 1676-1706.

[21] Ross, M. (2001). Does Oil Hinder Democracy? World Politics, 53, 325-361.

[22] Treich N. (2010). Risk-aversion and prudence in rent-seeking games. Public Choice, $145,339-349$.

[23] Tsui, K. (2011). More Oil, Less Democracy: Evidence from the Worldwide Crude Oil Discoveries. Economic Journal, 121, 89-115.

[24] Tullock G. (1980). Efficient rent-seeking. In: Towards a Theory of the Rent-Seeking Society, J. Buchanan, R. Tollison and G. Tullock (Eds.), 91-112. Texas A \& M University Press.

[25] Tullock G. (1967). The welfare costs of tarifs, monopolies, and theft. Western Economic Journal, 5, 224-232.

[26] van der Ploeg, R., R. Arezki and F. Toscani (2017). The shifting natural wealth of nations: The role of market orientation. OxCarre Working Papers 180, Oxford Centre for the Analysis of Resource Rich Economies, University of Oxford. 
[27] Wirl F. (1994). The dynamics of lobbying- a differential game. Public Choice, 80, 307323. 


\section{A Appendix}

\section{A.1 Existence of a unique MPE (proof of Proposition 3.1)}

Denote the stationary value function of player $\mathrm{i}$ as $V_{i}(z, R)$, then the Hamilton-JacobBellman equation of player $i(i=1,2)$ is

$$
r V_{i}(z, R)=\max _{x_{i}}\left[F_{i}\left(x_{i}, z\right)+\frac{\partial V_{i}}{\partial z} \cdot\left(x_{1}-(1+\varepsilon R) x_{2}\right)+\frac{\partial V_{i}}{\partial R}(\eta+\xi R)+\frac{1}{2} \sigma D^{2} V_{i} \sigma^{\prime}\right],
$$

with $\sigma=\left(\begin{array}{ll}\sigma_{z} z & \sigma_{R} R\end{array}\right)$, its transpose $\sigma^{T}=\left(\begin{array}{c}\sigma_{z} z \\ \sigma_{R} R\end{array}\right)$ and $D^{2} V_{i}$ the second order derivative.

Consider linear-quadratic value function

$$
V_{i}(z, R)=A_{i}+B_{i} z+\frac{C_{i}}{2} z^{2}+D_{i} R+\frac{E_{i}}{2} R^{2}+H_{i} z R
$$

then we have

$$
\begin{aligned}
& \frac{\partial V_{i}(z, R)}{\partial z}=B_{i}+C_{i} z+H_{i} R \\
& \frac{\partial V_{i}(z, R)}{\partial R}=D_{i}+E_{i} R+H_{i} z
\end{aligned}
$$

and

$$
D^{2} V_{i}=\left(\begin{array}{cc}
\frac{\partial^{2} V_{i}}{\partial z^{2}} & \frac{\partial^{2} V_{i}}{\partial z \partial R} \\
\frac{\partial^{2} V_{i}}{\partial z \partial R} & \frac{\partial^{2} V_{i}}{\partial R^{2}}
\end{array}\right)=\left(\begin{array}{cc}
C_{i} & H_{i} \\
H_{i} & E_{i}
\end{array}\right)
$$

Thus

$$
\Sigma_{i}=\frac{1}{2} \sigma D^{2} V_{i} \sigma^{T}=\frac{1}{2}\left[C_{i}\left(\sigma_{z} z\right)^{2}+2 H_{i} \sigma_{z} z \sigma_{R} R+E_{i}\left(\sigma_{R} R\right)^{2}\right] .
$$

Substituting the above functions into the HJB equation, it follows, for $i=1,2$

$$
\begin{aligned}
r V_{i}(z, R) & =\max _{x_{i}}\left[F_{i}\left(x_{i}, z\right)+\left(B_{i}+C_{i} z+H_{i} R\right) \cdot\left(x_{1}-(1+\varepsilon R) x_{2}\right)\right. \\
& \left.+\left(D_{i}+E_{i}+H_{i} z\right)(\eta+\xi R)+\Sigma_{i}\right] .
\end{aligned}
$$

The standard first order conditions yields the following optimal efforts:

$$
x_{1}(t)=\frac{1}{b} \frac{\partial V_{1}}{\partial z}=\frac{\left(B_{1}+C_{1} z+H_{1} R\right)}{b}
$$


and

$$
x_{2}(t)=-\frac{1+\varepsilon R}{b} \frac{\partial V_{2}}{\partial z}=\frac{-(1+\varepsilon R)\left(B_{2}+C_{2} z+H_{2} R\right)}{b} .
$$

Substituting $x_{1}$ and $x_{2}$ into the right hand side of HJB equations for both players and comparing the coefficients of the left and right hand sides, we have

$$
\left\{\begin{array}{l}
r A_{1}=a_{0}+\frac{B_{1}^{2}}{2 b}+\frac{B_{1} B_{2}}{b}+\eta D_{1}, \\
r B_{1}=a_{1}, \\
C_{1}=0, \\
r D_{1}=\frac{2 \varepsilon B_{1} B_{2}}{b}+\eta E_{1}+\xi D_{1}, \\
r E_{1}=\frac{\varepsilon^{2} B_{1} B_{2}}{b}+\left(\xi+\frac{\sigma_{R}^{2}}{2}\right) E_{1} \\
H_{1}=0
\end{array}\right.
$$

and

$$
\left\{\begin{array}{l}
r A_{2}=a_{0}+\frac{B_{2}^{2}}{2 b}+\frac{B_{1} B_{2}}{b}+\eta D_{2} \\
r B_{2}=-a_{1} \\
C_{2}=0 \\
r D_{2}=\frac{\varepsilon B_{2}^{2}}{b}+\eta E_{2}+\xi D_{2} \\
r E_{2}=\frac{\varepsilon^{2} B_{2}^{2}}{b}+\left(\sigma_{R}^{2}+2 \xi\right) E_{2} \\
H_{2}=0
\end{array}\right.
$$

Solving these systems yields

$$
\left\{\begin{array}{l}
C_{1}=0, \quad H_{1}=0, \quad B_{1}=\frac{a_{1}}{r}, \quad E_{1}=-\frac{2 \varepsilon^{2} a_{1}^{2}}{b r^{2}\left(r-2 \xi-\sigma_{R}^{2}\right)}, \\
D_{1}=\frac{2 \varepsilon a_{1}^{2}}{b r^{3}(r-\xi)}+\frac{\eta E_{1}}{r-\xi} \\
A_{1}=\frac{a_{0}}{r}-\frac{a_{1}^{2}}{2 b r^{3}}+\frac{\eta D_{1}}{r}
\end{array}\right.
$$


and

$$
\left\{\begin{array}{l}
C_{2}=0, \quad H_{2}=0, \quad B_{2}=-\frac{a_{1}}{r}, \quad E_{2}=\frac{\varepsilon^{2} a_{1}^{2}}{b r^{2}\left(r-2 \xi-\sigma_{R}^{2}\right)} \\
D_{2}=\frac{\varepsilon a_{1}^{2}}{b r^{2}(r-\xi)}+\frac{\eta E_{2}}{r-\xi} \\
A_{2}=\frac{a_{0}}{r}-\frac{a_{1}^{2}}{b r^{3}}+\frac{\eta D_{2}}{r} .
\end{array}\right.
$$

The current value functions are

$$
V_{1}(z, R)=A_{1}+B_{1} z+D_{1} R+\frac{E_{1}}{2} R^{2}, \quad V_{2}(z, R)=A_{2}+B_{2} z+D_{2} R+\frac{E_{2}}{2} R^{2} .
$$

The optimal choice of player 1 is thus

$$
x_{1}(t)=\frac{1}{b} \frac{\partial V_{1}}{\partial z}=\frac{B_{1}}{b}=\frac{a_{1}}{b r}
$$

and the optimal choice of player 2 is

$$
x_{2}^{*}(t)=-\frac{1+\varepsilon R(t)}{b} \frac{\partial V_{2}}{\partial z}=\frac{a_{1}(1+\varepsilon R)}{b r} .
$$

Substituting the optimal choices into the two state equations, we obtain the dynamic system (6). That finishes the proof.

\section{A.2 Stability of the MPE (proof of Propositions A.1 \& 3.3)}

Noticing that the expression of $R$ given in (7) can be rewritten as

$$
R(t)=R_{0} e^{\left(\xi-\frac{\sigma_{R}^{2}}{2}\right) t}+\eta \int_{0}^{t} e^{\left(\xi-\frac{\sigma_{R}^{2}}{2}\right)(t-s)+\sigma_{R}\left(W_{t}-W_{s}\right)} d s
$$

we can then rely on Boucekkine et al. (2018b), to claim that the first term is stable if and only if

$$
\xi-\frac{\sigma_{R}^{2}}{2}<0
$$

Thus, a straightforward result is that if $\eta=0$, the resource revenue process, as given by (18), is stochastically stable if and only if (9) holds. Here it is worth comparing this result with the ones obtained in the deterministic counterpart of our problem, as stated in Proposition 3.2. If $\eta=0$ (non-renewable resource case), then either the resource rev- 
enue process goes to zero when $\xi<0$ or it goes to $\infty$ when $\xi>0$. Under uncertainty, we show that noise is fully stabilizing in the latter case provided the revenue volatility, or uncertainty, is large enough. But this is far from a definitive result since the endogenous variable is the legislative state, $z$. The following proposition proves that (9) is enough to ensure the boundedness of the $z$-process whatever $\eta \geq 0$.

Proposition A.1. Suppose that condition (9) and $\sigma_{z}>0$ hold, then there exist $M_{R}=M_{R}\left(\xi, \sigma_{R}\right)>$ 0 and $M_{z}=M_{z}\left(\xi, \sigma_{R}, \sigma_{z}\right)>0$, such that, both stochastic processes $R$ and $z$ are almost surely bounded in the sense of absolute values:

$$
0 \leq R(t) \leq M_{R}, \quad|z(t)| \leq M_{z}, \quad \forall t \geq 0 .
$$

Thus in contrast to the deterministic case, one can assure the almost sure boundedness of the legislative state even in the case where $\xi>0$, that is even when the deterministic part of resource revenue dynamics leads to explosive rents. In our working example, the MPE feedback rules, $x_{i}(t), i=1,2$, only depend on resource revenues (because $a_{2}=0$ ), and therefore the deterministic part of the dynamics of the legislative state only depends on the latter variable. Proposition A.1 establishes that when the process of resource revenue is stochastically stable, the stochastic legislative state is almost surely bounded for any level of political uncertainty $\sigma_{z}$.

With this in mind, we can take a step further, and proceed to the computation of asymptotic invariant distribution. The results are summarized in the next proposition (again we use the mathematical apparatus developed in the Appendix B of Merton (1975), see the Appendix A.2.2).

Furthermore, note that in Proposition 3.3, we voluntarily pay attention to the case $\eta>0$ only. The reason for this is quite simple. If $\eta=0$, the density function (??) simplifies to

$$
\pi_{R}(R ; \eta=0)=\frac{n}{\sigma_{R}^{2}} R^{\frac{2}{\sigma_{R}^{2}}\left(\xi-\sigma_{R}^{2}\right)},
$$

but then it is impossible that

$$
\int_{0}^{\infty} \pi_{R}(R ; \eta=0) d R=1 .
$$

In other words, when $\eta=0$, the limit of the density function (??) can not serve as a 
density function. Nonetheless in this case, it is easy to show that ${ }^{15}$

\section{A.2.1 Proof of Proposition A.1}

In the following, we keep condition (9) and hence, we only need to study the second term of (18). Let $X(t)$ be the solution of the following homogenous stochastic equation

$$
\left\{\begin{array}{l}
d X(t)=\xi X(t) d t+\sigma_{R} X(t) d W_{t}, \forall t \geq s \\
X(s)=1
\end{array}\right.
$$

By Ito's Lemma, the solution satisfies

$$
\ln (X(t ; s))=\left(\xi-\frac{\sigma_{R}^{2}}{2}\right)(t-s)+\sigma_{R}\left(W_{t}-W_{s}\right)
$$

and

$$
\lim _{t \rightarrow \infty} \frac{\mathbf{E} \ln (X(t ; s))}{t}=\xi-\frac{\sigma_{R}^{2}}{2}<0
$$

under condition (9). Therefore, for any $\epsilon \in\left(0, \frac{\sigma_{R}^{2}}{2}-\xi\right)$, there exits $\delta=\delta(\epsilon)$, such that

$$
|X(t ; s)| \leq \delta e^{\left(\xi-\frac{\sigma_{R}^{2}}{2}+\epsilon\right)(t-s)}, \forall t \geq s
$$

Hence, we have

$$
\int_{0}^{t} X(t ; s) d s \leq \delta \int_{0}^{t} e^{\left(\xi-\frac{\sigma_{R}^{2}}{2}+\epsilon\right)(t-s)} d s=\frac{\delta}{\xi-\frac{\sigma_{R}^{2}}{2}+\epsilon}\left[1-e^{\left(\xi-\frac{\sigma_{R}^{2}}{2}+\epsilon\right) t}\right] .
$$

\footnotetext{
${ }^{15}$ With $\eta=0$, the process $R$ follows a linear homogenous stochastic differential equation:

$$
d R(t)=\xi R(t) d t+\sigma_{R} R d W_{t} .
$$

Boucekkine et al. (2018b) show that the $R$ process almost surely converges to its steady state $R_{\infty}=0$, provided $\xi-\frac{\sigma_{R}^{2}}{2}<0$. This means that, at the limit, the $z$ process in turn follows

$$
d z=\mu_{z} z d t+\sigma_{z} z d W
$$

with $\mu_{z}=0$, and hence $\mu_{z}-\frac{\sigma_{z}^{2}}{2}=-\frac{\sigma_{z}^{2}}{2}<0$ is always true. Thus, by Boucekkine, Pintus and Zou (2018) again, we have that process $z$ converges to its long run steady state $z_{\infty}=0$.
} 
Furthermore, taking limits on both sides, we have

$$
\lim _{t \rightarrow \infty} \eta \mathbf{E} \int_{0}^{t} X(t ; s) d s \leq \frac{\eta \delta}{\xi-\frac{\sigma_{R}^{2}}{2}+\epsilon} .
$$

Take $\epsilon=\frac{1}{2}\left(\xi-\frac{\sigma_{R}^{2}}{2}\right)$, then $\delta=\delta\left(\xi, \sigma_{R}\right)$ and

$$
\lim _{t \rightarrow \infty} \eta \int_{0}^{t} X(t ; s) d s \leq \eta H\left(\xi, \sigma_{R}\right)<+\infty
$$

where $H\left(\xi, \sigma_{R}\right)$ is a constant which depends on $\xi$ and $\sigma_{R}$ only. In other world, the second part of (18) is bounded under condition (9).

Combining the first and second parts together, it yields that condition (9) guarantees that function $R(t)$ is finite for any $t \geq 0$.

Substituting the above bounded results of $R(t)$ into the expression of $z(t)$ given in 7 , and applying the same analysis, we could conclude that $z(t)$ is also bounded given $-\sigma_{z}<0$. That finishes the proof.

\section{A.2.2 Proof of Proposition 3.3}

The proof of existence of steady state density distribution of stochastic process $R(t)$ is exactly the same as Merton (1975).

Given $R(t)$ is a diffusion process, its transition density function will satisfy the Kolmogorov-Foller-Planck "forward" equation. Let $P(R, t)$ as the conditional probability density for process $R(t)$ at time $t$, given initial condition $R(0)=R_{0}$. Then the corresponding Kolmogorov-Foller-Planck "forward" equation would be

$$
\frac{\partial P}{\partial t}=-\frac{\partial}{\partial R}[(\eta+\xi R) P(R, t)]+\frac{\partial^{2}}{\partial R^{2}}\left(\frac{\sigma_{R}^{2} R^{2}}{2} P(R, t)\right) .
$$

The above equation can be rewritten as

$$
\frac{\partial P}{\partial t}=\left(\sigma_{R}^{2}-\xi\right) P(R, t)+\left(4 \sigma_{R} R-\xi R-\eta\right) \frac{\partial P}{\partial R}+\frac{\sigma_{R}^{2} R^{2}}{2} \frac{\partial^{2}}{\partial R^{2}} P(R, t) .
$$


Suppose that $R$ has a steady state distribution, independent of $R_{0}$, then

$$
\lim _{t \rightarrow \infty} P(R, t)=\pi_{R}(R)
$$

and

$$
\lim _{t \rightarrow \infty} \frac{\partial P}{\partial t}=0 .
$$

Thus, the stationary density function $\pi(R)$ is the solution of the following second order differential equation:

$$
\left.0=\frac{d}{d R}\left[-\left(\eta+\xi_{R} R\right) \pi(R)\right]+\frac{d}{d R}\left(\frac{\sigma_{R}^{2} R^{2}}{2} \pi_{R}(R)\right)\right] .
$$

The rest will follow the same arguments as Appendix B of Merton (1975), except the inaccessible of one natural boundary $R=0$, where we recall the stochastic differential equation

$$
d R(t)=(\eta+\xi R) d t+\sigma_{R} R d B_{t},
$$

with $R \in\left[0, M_{R}\right]$. To finish this part of proof, we follow the method of Merton (1975, Page 390-391) that we "compare the stochastic process generated by" (21) "with another process which is known to have inaccessible boundaries and then to show that the probability that" $R$ "reaches its boundary" $R=0$ "is no larger than the probability that the comparison process reaches its" boundary.

Define a new process $X(t)=\ln (R)$. By Ito's Lemma, it follows from condition (9) that

$$
d X=\left(\frac{\eta}{R}+\xi-\frac{\sigma_{R}^{2}}{2}\right) d t+\sigma_{R} d B_{t},
$$

with $\xi-\frac{\sigma_{R}}{2}<0$.

Noticing that if $M_{R}>1$ and $R \in\left[1, M_{R}\right]$, by continuity, it is impossible that $R(t) \rightarrow 0$ as $t \rightarrow \infty$. Thus, we only need to consider the case $R \in\left[0, \min \left\{1, M_{R}\right\}\right]$.

Take $\delta=\frac{1}{2}\left(\frac{\sigma_{R}^{2}}{2}-\xi\right)>0$, then, provided $\eta>0$

$$
\frac{\eta}{R}+\xi-\sigma_{R}^{2} \geq \delta>0
$$


if and only if,

$$
R \leq \frac{2 \eta}{3\left(\frac{\sigma_{R}^{2}}{2}-\xi\right)}=\underline{R}
$$

Consider a Wiener process $W(t)$ with drift $\delta$ and variance $\sigma_{R}^{2}$ defined on the interval $[-\infty, \underline{R}]$ where $\underline{R}$ is a reflecting barrier. I.e.,

$$
d W(t)=\delta d t-\sigma_{R} d B_{t}
$$

for $W \in[-\infty, \underline{R}]$. Merton (1975, Page 391) and Cox and Miller (1968, page 223-225) have shown that such a process with $\delta>0$ has a non-degenerate steady state. Thus, $-\infty$ is an inaccessible boundary for $W$-process. Therefore, $-\infty$ is also an inaccessible boundary for $X$-process. Given $X(t)=\ln (R)$, thus, 0 is an inaccessible boundary for $R$-process, provided $\eta>0$.

For the process $z$, the same arguments apply as well. That completes the proof.

\section{A.2.3 Impact of uncertainty on the long-run}

Differentiating the $R$ - process density function in (10) with respect to $R$ yields

$$
\frac{d \pi_{R}(R ; \eta)}{d R}=\frac{2 n}{\sigma_{R}^{4}} \exp \left\{-\frac{2 \eta}{\sigma_{R}^{2} R}\right\} R^{2\left(\frac{\xi}{\sigma_{R}^{2}}-2\right)}\left[\left(\xi-\sigma_{R}^{2}\right) R+\eta\right] .
$$

Thus, if $\xi-\sigma_{R}^{2}<0$, we have

$$
\frac{d \pi_{R}(R ; \eta)}{d R} \gtreqless 0, \text { when } R \lesseqgtr \widehat{R}=\frac{\eta}{\sigma_{R}^{2}-\xi}(>0) .
$$

Following the argument of Jorgensen and Yeung (1996), the point $\widehat{R}$ is the most likely position of revenue. Similarly, differentiating the second density function in (10) with respect to $z$, we obtain

$$
\frac{d \pi_{z}(z)}{d z}=\frac{2 m}{\sigma_{z}^{2} z^{4}} \exp \left\{-\frac{2 a_{1} \varepsilon R(2+\varepsilon R)}{b r \sigma_{z}^{2}} \frac{1}{z}\right\}\left[-z+\frac{a_{1} \varepsilon R(2+\varepsilon R)}{b r \sigma_{z}^{2}}\right]
$$

And hence,

$$
\frac{d \pi_{z}(z)}{d z} \gtreqless 0 \text {, when } z \lesseqgtr \widehat{z}(R)=\frac{a_{1} \varepsilon R(2+\varepsilon R)}{b r \sigma_{z}^{2}}(\geq 0), \forall R \geq 0 \text {. }
$$




\section{A.3 Additional Tables}

Table 4: Ordered Logit Estimates

\begin{tabular}{|c|c|c|c|c|c|c|}
\hline & $\begin{array}{c}(1) \\
\Delta F L_{i t} \\
\end{array}$ & $\begin{array}{c}(2) \\
\Delta F L_{i t}\end{array}$ & $\begin{array}{c}(3) \\
\Delta F L_{i t}\end{array}$ & $\begin{array}{c}(4) \\
\Delta F L_{i t}\end{array}$ & $\begin{array}{c}(5) \\
\Delta F L_{i t}\end{array}$ & $\begin{array}{c}(6) \\
\Delta F L_{i t}\end{array}$ \\
\hline$F L_{i, t-1} x\left(1-F L_{i, t-1}\right)$ & $\begin{array}{c}7.4568^{* * *} \\
(0.7808)\end{array}$ & $\begin{array}{c}6.5510^{* * *} \\
(0.8973)\end{array}$ & & & $\begin{array}{c}9.7357^{* * *} \\
(1.2105)\end{array}$ & $\begin{array}{c}9.7670^{* * *} \\
(2.6067)\end{array}$ \\
\hline$R E G_{F} L_{i, t-1}-F L_{i, t-1}$ & $\begin{array}{c}3.8835^{* * *} \\
(0.4337)\end{array}$ & $\begin{array}{c}3.7604^{* * *} \\
(0.4844)\end{array}$ & $\begin{array}{c}4.2900^{* * *} \\
(0.6911)\end{array}$ & $\begin{array}{c}3.7952^{* * *} \\
(0.7629)\end{array}$ & $\begin{array}{c}5.9935^{* * *} \\
(0.6519)\end{array}$ & $\begin{array}{c}0.6710 \\
(1.1999)\end{array}$ \\
\hline$R E S O U R C E_{V} O L A T I L I T Y_{i, t}$ & $\begin{array}{c}-0.0167^{* *} \\
(0.0065)\end{array}$ & $\begin{array}{c}-0.0175^{* *} \\
(0.0068)\end{array}$ & $\begin{array}{c}-0.0176^{* * *} \\
(0.0066)\end{array}$ & $\begin{array}{c}-0.0175^{* *} \\
(0.0069)\end{array}$ & $\begin{array}{c}-0.0167^{*} \\
(0.0088)\end{array}$ & $\begin{array}{c}-0.0253^{* *} \\
(0.0127)\end{array}$ \\
\hline$R I G H T_{i, t}$ & & $\begin{array}{c}0.7358^{* * *} \\
(0.2025)\end{array}$ & & $\begin{array}{c}0.7362^{* * *} \\
(0.2024)\end{array}$ & $\begin{array}{c}0.7628^{* * *} \\
(0.2181)\end{array}$ & $\begin{array}{l}-0.0487 \\
(0.4894)\end{array}$ \\
\hline FIRSTYEAR ${ }_{i, t}$ & & $\begin{array}{c}0.1121 \\
(0.1384)\end{array}$ & & $\begin{array}{c}0.1123 \\
(0.1386)\end{array}$ & $\begin{array}{c}0.2391 \\
(0.1691)\end{array}$ & $\begin{array}{l}-0.1189 \\
(0.2636)\end{array}$ \\
\hline$C U R R E N C Y_{i, t}$ & & $\begin{array}{l}-0.2070 \\
(0.1659)\end{array}$ & & $\begin{array}{c}-0.2061 \\
(0.1661)\end{array}$ & $\begin{array}{c}-0.3010 \\
(0.1913)\end{array}$ & $\begin{array}{l}-0.1070 \\
(0.3599)\end{array}$ \\
\hline$O P E N_{i, t}$ & & $\begin{array}{c}-0.1014 \\
(0.1092)\end{array}$ & & $\begin{array}{c}-0.1031 \\
(0.1121)\end{array}$ & $\begin{array}{c}-0.0526 \\
(0.1185)\end{array}$ & $\begin{array}{c}-0.3665 \\
(0.2892)\end{array}$ \\
\hline$L E F T_{i, t}$ & & $\begin{array}{c}0.5536^{* * *} \\
(0.2086)\end{array}$ & & $\begin{array}{c}0.5534^{* * *} \\
(0.2088)\end{array}$ & $\begin{array}{c}0.4570^{*} \\
(0.2398)\end{array}$ & $\begin{array}{l}-0.1336 \\
(0.4741)\end{array}$ \\
\hline$B A N K_{i, t}$ & & $\begin{array}{l}0.3171^{* *} \\
(0.1536)\end{array}$ & & $\begin{array}{l}0.3173^{* *} \\
(0.1537)\end{array}$ & $\begin{array}{c}0.1673 \\
(0.1762)\end{array}$ & $\begin{array}{c}0.2251 \\
(0.3343)\end{array}$ \\
\hline INFLATION $N_{i, t}$ & & $\begin{array}{l}0.4642^{* *} \\
(0.2131)\end{array}$ & & $\begin{array}{c}0.4664^{* *} \\
(0.2158)\end{array}$ & $\begin{array}{c}0.2964 \\
(0.2215)\end{array}$ & $\begin{array}{c}1.1207 \\
(0.7042)\end{array}$ \\
\hline$F L_{i, t-1}$ & & & $\begin{array}{c}7.6628^{* * *} \\
(0.8063)\end{array}$ & $\begin{array}{c}6.5735^{* * *} \\
(0.9655)\end{array}$ & & \\
\hline$\left(F L_{i, t-1}\right)^{2}$ & & & $\begin{array}{c}-7.3461^{* * *} \\
(0.8019) \\
\end{array}$ & $\begin{array}{c}-6.5444^{* * *} \\
(0.9044) \\
\end{array}$ & & \\
\hline Log-Likelihood & -2764.899 & -2528.849 & -2764.555 & -2528.847 & -1919.964 & -559.187 \\
\hline Sample-Size & 1969 & 1780 & 1969 & 1780 & 1255 & 525 \\
\hline
\end{tabular}

Notes: ${ }^{* * *}, * *$, and ${ }^{*}$ indicate statistical significance at the $1 \%, 5 \%$ and $10 \%$ levels respectively. Standard Errors are adjusted for country level clustering. 
Table 5: Joint Likelihood estimation Estimates

\begin{tabular}{|c|c|c|c|c|}
\hline & $\begin{array}{c}(1) \\
\Delta F L_{i t}\end{array}$ & $\begin{array}{c}(2) \\
\Delta F L_{i t} \\
\end{array}$ & $\begin{array}{c}(3) \\
\Delta F L_{i t}\end{array}$ & $\begin{array}{c}(4) \\
\Delta F L_{i t}\end{array}$ \\
\hline $\begin{array}{l}\Delta F L_{i t} \\
F L(t-1) *(1-F L(t-1))\end{array}$ & $\begin{array}{c}4.2759^{* * *} \\
(0.6063)\end{array}$ & $\begin{array}{c}4.2568^{* * *} \\
(0.6051)\end{array}$ & & \\
\hline RESOURCE $E_{V} O L A T I L I T Y_{i, t}$ & $\begin{array}{c}-0.0185^{* * *} \\
(0.0057)\end{array}$ & $\begin{array}{c}-0.0171^{* * *} \\
(0.0062)\end{array}$ & $\begin{array}{c}-0.0182^{* * * *} \\
(0.0056)\end{array}$ & $\begin{array}{c}-0.0172^{* * *} \\
(0.0062)\end{array}$ \\
\hline$R I G H T_{i, t}$ & $\begin{array}{c}0.4240^{* * *} \\
(0.1167)\end{array}$ & $\begin{array}{c}0.4240^{* * *} \\
(0.1168)\end{array}$ & $\begin{array}{c}0.4416^{* * *} \\
(0.1201)\end{array}$ & $\begin{array}{c}0.4420^{* * *} \\
(0.1203)\end{array}$ \\
\hline FIRSTYEAR $R_{i, t}$ & $\begin{array}{c}0.0553 \\
(0.1243)\end{array}$ & $\begin{array}{c}0.0539 \\
(0.1242)\end{array}$ & $\begin{array}{c}0.0627 \\
(0.1238)\end{array}$ & $\begin{array}{c}0.0613 \\
(0.1236)\end{array}$ \\
\hline$C U R R E N C Y_{i, t}$ & $\begin{array}{c}-0.2011 \\
(0.1288)\end{array}$ & $\begin{array}{l}-0.2018 \\
(0.1297)\end{array}$ & $\begin{array}{c}-0.2062 \\
(0.1282)\end{array}$ & $\begin{array}{l}-0.2079 \\
(0.1293)\end{array}$ \\
\hline$L E F T_{i, t}$ & $\begin{array}{c}0.3445^{* * *} \\
(0.1131)\end{array}$ & $\begin{array}{c}0.3462^{* * *} \\
(0.1127)\end{array}$ & $\begin{array}{c}0.3565^{* * *} \\
(0.1174)\end{array}$ & $\begin{array}{c}0.3578^{* * *} \\
(0.1170)\end{array}$ \\
\hline$B A N K_{i, t}$ & $\begin{array}{l}0.2052^{*} \\
(0.1196)\end{array}$ & $\begin{array}{l}0.2077^{*} \\
(0.1207)\end{array}$ & $\begin{array}{l}0.2100^{*} \\
(0.1173)\end{array}$ & $\begin{array}{l}0.2114^{*} \\
(0.1184)\end{array}$ \\
\hline$I_{N F L A T I O N}, t$ & $\begin{array}{c}0.4354^{* * *} \\
(0.1503)\end{array}$ & $\begin{array}{c}0.4317^{* * *} \\
(0.1499)\end{array}$ & $\begin{array}{c}0.4078^{* * *} \\
(0.1518)\end{array}$ & $\begin{array}{c}0.4017^{* * *} \\
(0.1515)\end{array}$ \\
\hline$R E G_{F} L_{i, t-1}-F L_{i, t-1}$ & $\begin{array}{c}1.6279^{* * *} \\
(0.2473)\end{array}$ & $\begin{array}{c}1.6264^{* * *} \\
(0.2463)\end{array}$ & $\begin{array}{c}1.3474^{* * *} \\
(0.4165)\end{array}$ & $\begin{array}{c}1.3499^{* * *} \\
(0.4168)\end{array}$ \\
\hline$O P E N_{i, t}$ & $\begin{array}{c}-0.0132 \\
(0.0484)\end{array}$ & $\begin{array}{c}-0.0137 \\
(0.0486)\end{array}$ & $\begin{array}{l}-0.0072 \\
(0.0486)\end{array}$ & $\begin{array}{c}-0.0074 \\
(0.0488)\end{array}$ \\
\hline M[ifs] & $\begin{array}{c}0.0155 \\
(0.0232)\end{array}$ & $\begin{array}{c}0.0110 \\
(0.0336)\end{array}$ & $\begin{array}{c}0.0179 \\
(0.0234)\end{array}$ & $\begin{array}{c}0.0156 \\
(0.0354)\end{array}$ \\
\hline$F L_{i, t-1}$ & & & $\begin{array}{c}3.9840^{* * *} \\
(0.6862)\end{array}$ & $\begin{array}{c}3.9649^{* * *} \\
(0.6859)\end{array}$ \\
\hline$F L_{i, t-1}^{2}$ & & & $\begin{array}{c}-4.2562^{* * *} \\
(0.6045)\end{array}$ & $\begin{array}{c}-4.2337^{* * *} \\
(0.6038)\end{array}$ \\
\hline$\lambda$ & $\begin{array}{l}7.4771^{* *} \\
(3.1984) \\
\end{array}$ & $\begin{array}{c}6.9593 \\
(5.0845) \\
\end{array}$ & $\begin{array}{l}7.3209^{* *} \\
(3.1313) \\
\end{array}$ & $\begin{array}{c}6.7127 \\
(4.9349) \\
\end{array}$ \\
\hline OILRESERVES $S_{i, t}$ & $\begin{array}{l}2.6717^{*} \\
(1.5203)\end{array}$ & & $\begin{array}{l}2.6725^{*} \\
(1.5312)\end{array}$ & \\
\hline$F L(t-1) *(1-F L(t-1))$ & $\begin{array}{l}-2.1691^{*} \\
(1.2203)\end{array}$ & $\begin{array}{l}-2.2422 \\
(1.7225)\end{array}$ & & \\
\hline$R E G_{F} L_{i, t-1}-F L_{i, t-1}$ & $\begin{array}{l}-0.8855 \\
(0.5570)\end{array}$ & $\begin{array}{l}-0.9537 \\
(0.6841)\end{array}$ & $\begin{array}{c}0.1762 \\
(0.6643)\end{array}$ & $\begin{array}{c}0.7021 \\
(0.6992)\end{array}$ \\
\hline$R I G H T_{i, t}$ & $\begin{array}{l}-0.0270 \\
(0.2533)\end{array}$ & $\begin{array}{l}-0.0708 \\
(0.3277)\end{array}$ & $\begin{array}{l}-0.0323 \\
(0.2505)\end{array}$ & $\begin{array}{l}-0.0653 \\
(0.3274)\end{array}$ \\
\hline FIRSTYEAR $R_{i, t}$ & $\begin{array}{l}-0.1720 \\
(0.1109)\end{array}$ & $\begin{array}{l}-0.4424^{*} \\
(0.2561)\end{array}$ & $\begin{array}{l}-0.1733 \\
(0.1102)\end{array}$ & $\begin{array}{l}-0.4508^{*} \\
(0.2565)\end{array}$ \\
\hline$C U R R E N C Y_{i, t}$ & $\begin{array}{l}-0.1662 \\
(0.3145)\end{array}$ & $\begin{array}{l}-0.3320^{*} \\
(0.1935)\end{array}$ & $\begin{array}{l}-0.1421 \\
(0.3117)\end{array}$ & $\begin{array}{l}-0.2892 \\
(0.1859)\end{array}$ \\
\hline$L E F T_{i, t}$ & $\begin{array}{l}-0.0830 \\
(0.2366)\end{array}$ & $\begin{array}{c}-0.1319 \\
(0.2802)\end{array}$ & $\begin{array}{l}-0.0951 \\
(0.2347)\end{array}$ & $\begin{array}{l}-0.1508 \\
(0.2765)\end{array}$ \\
\hline$B A N K_{i, t}$ & $\begin{array}{c}0.0304 \\
(0.3260)\end{array}$ & $\begin{array}{c}-0.3857^{* *} \\
(0.1721)\end{array}$ & $\begin{array}{c}0.0342 \\
(0.3248)\end{array}$ & $\begin{array}{c}-0.3726^{* *} \\
(0.1693)\end{array}$ \\
\hline$I_{N F L A T I O N}$ & $\begin{array}{l}-0.1269 \\
(0.3394)\end{array}$ & $\begin{array}{l}-0.7534^{*} \\
(0.4446)\end{array}$ & $\begin{array}{l}-0.0517 \\
(0.3585)\end{array}$ & $\begin{array}{l}-0.6289 \\
(0.4322)\end{array}$ \\
\hline$O P E N_{i, t}$ & $\begin{array}{l}-0.1299 \\
(0.1583)\end{array}$ & $\begin{array}{c}0.0515 \\
(0.1584)\end{array}$ & $\begin{array}{l}-0.1654 \\
(0.1523)\end{array}$ & $\begin{array}{l}-0.0127 \\
(0.1692)\end{array}$ \\
\hline$L A G_{R} E S O U R C E_{V} O L A T I L I T Y_{i, t}$ & & $\begin{array}{l}0.5250^{* *} \\
(0.2489)\end{array}$ & & $\begin{array}{l}0.5245^{* *} \\
(0.2500)\end{array}$ \\
\hline$F L_{i, t-1}$ & & & $\begin{array}{l}-1.4877 \\
(0.9832)\end{array}$ & $\begin{array}{l}-1.0408 \\
(1.5415)\end{array}$ \\
\hline$F L_{i, t-1}^{2}$ & & & $\begin{array}{l}2.3877^{*} \\
(1.3092)\end{array}$ & $\begin{array}{c}2.4207 \\
(1.7825)\end{array}$ \\
\hline Log-Likelihood & -6642.745 & -7570.684 & -6641.653 & -7569.179 \\
\hline Sample-Size & 1780 & 1780 & 1780 & 1780 \\
\hline Error Correlation & 0.011 & 0.008 & 0.013 & 0.011 \\
\hline
\end{tabular}

Notes: ${ }^{* * *}, * *$, and ${ }^{*}$ indicate statistical significance at the $1 \%, 5 \%$ and $10 \%$ levels respectively. Standard Errors are adjusted for country level clustering. 